\title{
Benchmarking of several material constitutive models for tribology, wear, and other mechanical deformation simulations of Ti6Al4V
}

\author{
Cen Liuª, Saurav Goel ${ }^{a^{*}}$, Iñigo Llavori ${ }^{\mathrm{b}}$, Pietro Stolfc, Claudiu Giuscaa ${ }^{\mathrm{a}}$, Alaitz \\ Zabala $^{b}$, Joern Kohlscheen ${ }^{d}$, Jose Mario Paivac, Jose L Endrino ${ }^{a}$, Stephen C. \\ Veldhuis ${ }^{c}$ and German S. Fox Rabinovich ${ }^{c}$
}

\author{
${ }^{a}$ School of Aerospace, Transport and Manufacturing, Cranfield University, MK430AL, UK \\ ${ }^{b}$ Surface Technologies, Mondragon University, Loramendi 4, 20500 Arrasate, Mondragon, Spain \\ ${ }^{c}$ McMaster Manufacturing Research Institute, (MMRI), McMaster University, Hamilton, Ontario, Canada \\ ${ }^{d}$ Kennametal Shared Services Gmbh, Altweiherstr 27-31, Ebermannstadt 91320, Germany \\ * Corresponding author. Tel.: +44-1234-754132; E-mail address: saurav.goel@ cranfield.ac.uk
}

\begin{abstract}
Use of an alpha-beta (multiphase HCP-BCC) titanium alloy, Ti6Al4V, is ubiquitous in a wide range of engineering applications. The previous decade of finite element analysis research on various titanium alloys for numerous biomedical applications especially in the field of orthopedics has led to the development of more than half a dozen material constitutive models, with no comparison available between them. Part of this problem stems from the complexity of developing a vectorised user-defined material subroutine (VUMAT) and the different conditions (strain rate, temperature and composition of material) in which these models are experimentally informed. This paper examines the extant literature to review these models and provides quantitative benchmarking against the tabulated material model and a power law model of Ti6Al4V taking the test case of a uniaxial tensile and cutting simulation.
\end{abstract}

Keywords: Ti6Al4V; Material models; Johnson-Cook model; Zerilli Armstrong model; Voyiadjis-Abed model; tensile test; cutting 


\section{Introduction}

The ubiquitous use of titanium alloys in disparate fields like aerospace, automotive and the biomedical industry makes research on material characteristics of Ti6Al4V rewarding. In addition to achieving lighter weight, high corrosion resistance and high specific strength makes titanium alloys an ideal choice for biomedical manufacturing (Inagaki, Takechi et al. 2014). However, machining titanium alloys is a daunting task and they are generally referred to as "difficult to machine" materials. As a continuous research effort in improving our understanding on the material response of Ti6Al4V under different loading conditions, finite element analysis (FEA) has become an established simulation tool for predictive assessment of different kinds of manufacturing and material characterisation processes.

This kind of research is helpful in identification of the right combination of tooling material, optimisation of the processing window and development of strategies for suppressing tool wear which are all major research drivers in manufacturing.

In modern competitive markets, many industries have developed commercial softwares to perform FEA, each having their own advantages. Beside many others, the most common FEA software packages that are used to simulate machining processes are DEFORM, AdvantEdge, Abaqus, ANSYS and LS-DYNA. Usually, these codes have their own material library database built on an experimentally observed understanding of the material's behaviour under a given set of stress-strain conditions. In many situations, where complex material models are proposed, user subroutines are to be coded to work in these packages as incorporation of all material models within one package will make the software extremely bulky and complicated. Moreover, it is a continuous process, for instance over the past few years, more than half a dozen material constitutive models have been proposed for Ti6Al4V alone and it is high time 
that these models be benchmarked and compared to assert their proximity with each other. Some of the notable material models proposed for Ti6Al4V are the Arrheniustype constitutive equation (Mosleh, Mikhaylovskaya et al. 2017), the Field-Backofen model, the Khan-Huang-Liang model, the Mechanical Threshold Stress model (Kotkunde, Deole et al. 2014), the Johnson-Cook model (Yadav, Bajpai et al. 2017), the Multi-Branch model (Yameogo, Haddag et al. 2017), the Tangent hyperbolic model (Xiulin, Shiguang et al. 2015), the Voyiadjis-Abed model (Tabei, Abed et al. 2017), the Zerilli-Armstrong model (Che, Zhou et al. 2018), the Baker Modification of EI-Magd model (Alvarez, Domingo et al. 2011) and the Cuitino and Ortiz model (Man, Ren et al. 2012).

However, it may be noted that these material models are developed under different experimental conditions and due to this, it is challenging to say which particular material model is the best. It is also worth noting that the implementation of all these complex material models is not that straightforward and developing the user subroutine like VUMAT consumes significant time for testing each of the models. Consequently, the motivation of this paper was to compare several of these material models to establish the variation in the results presented by them for a given problem and then to benchmark the models against the predictions made by commercial codes like AdvantEdge and DEFORM. These two are commercially popular codes used by the machining community and have their own way of describing the material constitutive model, AdvantEdge, for example, implements the Cuitino and Ortiz model (Man, Ren et al. 2012) while DEFORM implements a tabulated material model of the form $\bar{\sigma}=$ $\bar{\sigma}(\bar{\varepsilon}, \dot{\varepsilon}, T)$, where $\bar{\sigma}, \bar{\varepsilon}, \dot{\varepsilon}$ and T refer to flow stress, equivalent plastic strain, equivalent plastic strain rate and temperature respectively. What's interesting is that AdvantEdge calculates the dynamic equilibrium in time by an explicit time integration method using 
a Lagrangian finite element formulation whilst DEFORM is an Implicit solver employing the Newton Raphson technique, although both software can use tetrahedron (3D), and rectangle (2D) element types.

\section{Literature review on Ti6Al4V}

Ti6Al4V, an $\alpha+\beta$ titanium alloy which was first developed in the 1950s (Leyens and Peters 2003), is composed of five main chemical elements: Ti, Al, V, Fe, C and the percentage of each element varies depending on the material sample (Cai, Wang et al. 2016, Che, Zhou et al. 2018). The research on the material behaviour of Ti6Al4V has primarily focused on how temperature, strain rate or microstructure of the alloy influences the elastic-plastic behaviour. It has also been reported that Ti6Al4V shows a high temperature sensitivity and strain hardening (Lee and Lin 1998). Based on these experiments, material constitutive models of Ti6Al4V are developed, incorporating these different effects and three basic forms of constitutive equations namely the Johnson-Cook (JC) model, the Zerilli-Armstrong (ZA) model and the Voyiadjis-Abed (VA) model are most notably proposed. As for the JC model, there are two variants (different parameters) reported in the literature which are henceforth termed as JC-1 and JC-2, this way the paper compares these four material models and benchmarks them against the Cuitino and Ortiz model, and tabulated material model as implemented in commercial codes AdvantEdge and DEFORM respectively.

\subsection{Description of the material constitutive models}

\subsubsection{Johnson-Cook (JC) model}

The Johnson-Cook (JC) model is the most widely used model used to describe metal plasticity in machining. Also, the JC model needs only a few parameters to describe the material behaviour, which has made it a popular choice. 
The basic form of the JC material model is described as follows (Rashid, Goel et al. 2013):

$$
\bar{\sigma}=\left(A+B \bar{\varepsilon}^{n}\right)\left(1+C\left[\ln \left(\frac{\dot{\varepsilon}}{\varepsilon_{0}}\right)\right]\right)\left(\frac{\dot{\varepsilon}}{\dot{\varepsilon}_{0}}\right)^{\alpha}\left(D-E T^{* m}\right)
$$

where $T^{* \mathrm{~m}}=\frac{T-T_{\text {ref }}}{T_{\text {melt }}-T_{\text {ref }}} \quad$ and $\quad D=D_{0}^{k(T-T b)^{\beta}}$

The above universal form of the $\mathrm{JC}$ model reduces to the following equation by taking $D_{0}$ and $E$ as 1 and $\alpha$ as 0 .

$$
\sigma=\left(A+B \varepsilon^{n}\right)\left(1+C \ln \dot{\varepsilon}^{*}\right)\left(1-T^{* m}\right)
$$

where $\dot{\varepsilon}^{*}$ and $T^{* m}$ refer to strain rate and homologous temperature respectively while, $A, B, C, n, m$ represents relevant material constants respectively, so that the terms, $\left(A+B \varepsilon^{n}\right)$ represents the strain hardening effect, $\left(1+C \ln \dot{\varepsilon}^{*}\right)$ describes the strain rate effect and $\left(1-T^{* m}\right)$ refers to the thermal softening effect. The equation for $\dot{\varepsilon}^{*}$ is as follows:

$$
\dot{\varepsilon}^{*}=\frac{\dot{\varepsilon}}{\dot{\varepsilon}_{0}}
$$

In the past, there have been two different parametrisations (shown in Table 1) proposed for Ti6Al4V by two different research groups and both these variants are included as a comparison in this work. These two variants of the JC model are based on different conditions. The JC-1 constants were obtained at a temperature of $323 \mathrm{~K}$ and at a strain rate of $0.01 / \mathrm{s}$ and the JC-2 constants were based on Hopkinson bar data and the determined at a temperature $298 \mathrm{~K}$ and at constant strain rates of 5000/s and 1/s. 
Table 1 Different variants of JC model proposed for Ti6Al4V (KOTKUNDE 2012) (Gu, Dong et al. 2015)

\begin{tabular}{cccccccccc}
\hline Model & $\begin{array}{c}A \\
(\mathrm{MPa})\end{array}$ & $\begin{array}{c}B \\
(\mathrm{MPa})\end{array}$ & $n$ & $m$ & $C$ & $\begin{array}{c}\dot{\varepsilon}_{0}(\mathrm{~s}- \\
1)\end{array}$ & $T_{\text {ref }}(\mathrm{K})$ & $T_{\text {melt }}(\mathrm{K})$ & Reference \\
\hline JC-1 & 896.4 & 649.5 & 0.3867 & 0.7579 & 0.0093 & 1 & 323 & 1923 & $\begin{array}{c}\text { (KOTKUNDE } \\
\text { 2012) }\end{array}$ \\
JC-2 & 1098 & 1092 & 0.93 & 1.1 & 0.014 & 1 & 298 & 1878 & $\begin{array}{c}\text { (Gu, Dong et } \\
\text { al. 2015) }\end{array}$ \\
\hline
\end{tabular}

\subsubsection{Zerilli-Armstrong (ZA) model}

As a physically based material model, the Zerilli-Armstrong (ZA) model can predict stress in material with different microstructures such as the face centred cubic (FCC) or the body-centred cubic (BCC) structure. It is also straightforward to implement, and material constants can be obtained from the published literature. The basic form of the ZA model is as follows with the parameters tested in this work, to describe Ti6Al4V shown in Table 2:

$$
\bar{\sigma}=\alpha+C_{1} \exp \left(-C_{3} T+C_{4} T \ln \dot{\varepsilon}\right)+C_{5} \bar{\varepsilon}^{n}
$$

Table 2 Constants used in general Zerilli-Armstrong (ZA) model (Özel and Karpat 2007)

\begin{tabular}{ccccccc}
\hline Parameter & $\alpha(\mathrm{MPa})$ & $C_{l}(\mathrm{MPa})$ & $C_{3}(1 / \mathrm{K})$ & $C_{4}(1 / \mathrm{K})$ & $C_{5}(\mathrm{MPa})$ & $n$ \\
\hline value & 740 & 240 & 0.0024 & 0.00043 & 656 & 0.5 \\
\hline
\end{tabular}

Subsequently, (Cai, Wang et al. 2016, Che, Zhou et al. 2018) proposed a modified ZA model in order to predict the flow stress of Ti6Al4V alloy in the $\alpha+\beta$ phase region and the model formula was expressed as follows with the parameter values shown in Table 3:

$$
\sigma=\left(C_{1}+C_{2} \varepsilon^{n}\right) \exp \left\{-\left(C_{3}+C_{4} \varepsilon\right) T^{*}+\left(C_{5}+C_{6} T^{*}\right) \ln \dot{\varepsilon}^{*}\right\}
$$

where $C_{1}, C_{2}, C_{3}, C_{4}, C_{5}, C_{6}$ are parameters of this material model, and they are related to different effects which influence the material behaviour. 
Table 3 Constants used in ZA model (KOTKUNDE 2012, Cai, Wang et al. 2016)

\begin{tabular}{cccccccc}
\hline Parameter & $C_{1}$ & $C_{2}$ & $C_{3}$ & $C_{4}$ & $C_{5}$ & $C_{6}$ & $n$ \\
\hline value & 869.4 & 640.50 & 0.0013 & $-9.57 \times 10^{-4}$ & 0.0095 & $6.94 \times 10^{-6}$ & 0.3867 \\
\hline
\end{tabular}

\subsubsection{Voyiadjis-Abed model (VA) model}

The Voyiadjis-Abed model was developed to investigate the thermo-viscoplastic behaviour of material under a wide range of machining conditions and the experiments were based on three kinds of Ti6Al4V alloys (Tabei, Abed et al. 2017) as shown in Table 4:

Table 4 Ti6Al4V alloy with different chemical composition (Tabei, Abed et al. 2017)

\begin{tabular}{|c|c|c|c|c|c|c|c|c|c|}
\hline $\mathrm{Ti}$ & $\mathrm{Al}$ & V & $\mathrm{Fe}$ & $\mathrm{O}$ & $\mathrm{C}$ & $\mathrm{N}$ & $\mathrm{H}$ & Other & Reference \\
\hline 89.5193 & 6.1 & 4.0 & 0.2 & 0.15 & 0.014 & 0.008 & 0.0057 & $<0.003$ & $\begin{array}{c}\text { (Lee and Lin } \\
\text { 1998) }\end{array}$ \\
\hline 89.753 & 6.21 & 3.61 & 0.21 & 0.19 & 0.01 & 0.01 & 0.006 & $<0.001$ & $\begin{array}{c}\text { (Nemat- } \\
\text { Nasser, Guo } \\
\text { et al. 2001) }\end{array}$ \\
\hline 89.4944 & 6.3 & 3.86 & 0.18 & 0.112 & 0.045 & 0.003 & 0.0026 & $<0.003$ & $\begin{array}{c}\text { (Khan, } \\
\text { Kazmi et al. } \\
2007)\end{array}$ \\
\hline
\end{tabular}

$$
\sigma=c_{1}+c_{2} \varepsilon_{P}^{c_{3}}+c_{4}\left(1-\left(-c_{5} T \ln \frac{\dot{\varepsilon}_{p}}{\dot{\varepsilon}_{p}^{* Y}}\right)^{\frac{1}{q_{1}}}\right)^{\frac{1}{q_{2}}}+c_{6} \varepsilon_{p}^{c_{7}}\left(1-\left(-c_{5} T \ln \frac{\dot{\varepsilon}_{p}}{\dot{\varepsilon}_{p}^{* H}}\right)^{\frac{1}{q_{1}}}\right)^{\frac{1}{q_{2}}}
$$

The parameters $c_{1}$ to $c_{7}$ are related to internal microstructure parameters of materials, such as grain size, Burgers vector and dislocation density (Tabei, Abed et al. 2017). For different Ti6Al4V alloys $c_{1}$ to $c_{7}$ have different values, which are listed in Table 5 . $q_{1}$ and $q_{2}$ are larger than 1 and 0 , and less than 2 and 1 respectively. In this study, $q_{1}$ was taken as 1.5 and $q_{2}$ was taken as 1.0 and it may be worth in future work to optimise this parameter. 
Table 5 Constants used in VA model (Tabei, Abed et al. 2017)

\begin{tabular}{|c|c|c|c|c|c|c|c|c|c|}
\hline $\begin{array}{c}c_{1}(M P a \\
)\end{array}$ & $\begin{array}{c}c_{2}(M P a \\
)\end{array}$ & $c_{3}$ & $\begin{array}{c}c_{4}(M P a \\
)\end{array}$ & $c_{5}$ & $\begin{array}{c}c_{6}(M P a \\
)\end{array}$ & $c_{7}$ & $\dot{\varepsilon}_{p}^{* Y}$ & $\dot{\varepsilon}_{p}^{* H}$ & $\begin{array}{c}\text { Referenc } \\
e \\
\end{array}$ \\
\hline 170 & 800 & $\begin{array}{c}0.1 \\
1\end{array}$ & 700 & $\begin{array}{c}4.2 \times 10 \\
-5\end{array}$ & 160 & $\begin{array}{c}0 . \\
5\end{array}$ & $\underset{1}{1.16 \times 10^{1}}$ & $\begin{array}{c}2.6 \times 10^{1} \\
3\end{array}$ & $\begin{array}{c}\text { (Lee and } \\
\text { Lin } \\
1998)\end{array}$ \\
\hline 30 & 500 & $\begin{array}{c}0.1 \\
1\end{array}$ & 1400 & $\begin{array}{c}4.2 \times 10 \\
-5\end{array}$ & 1100 & $\begin{array}{c}0 . \\
5\end{array}$ & $\underset{1}{1.16 \times 10^{1}}$ & $\begin{array}{c}2.6 \times 10^{1} \\
3\end{array}$ & $\begin{array}{l}\text { (Nemat- } \\
\text { Nasser, } \\
\text { Guo et al. } \\
\text { 2001) }\end{array}$ \\
\hline 50 & 750 & $\begin{array}{c}0.1 \\
1\end{array}$ & 1030 & $\begin{array}{c}4.2 \times 10 \\
-5\end{array}$ & 1100 & $\begin{array}{c}0 . \\
5\end{array}$ & $\underset{1}{1.16 \times 10^{1}}$ & $\frac{2.6 \times 10^{1}}{3}$ & $\begin{array}{l}\text { (Khan, } \\
\text { Kazmi et } \\
\text { al. 2007) }\end{array}$ \\
\hline
\end{tabular}

In the three variants of the VA model available in the literature shown in Table 5, (Lee and Lin 1998) performed a set of compression tests on Ti64 at a constant strain rate of $2 \times 10^{3} \mathrm{~s}^{-1}$ and in the temperature range from $700{ }^{\circ} \mathrm{C}$ to $1100^{\circ} \mathrm{C}$. (Nemat-Nasser, Guo et al. 2001) conducted a series of compression tests in the range of $10^{-3}$ to $6000 \mathrm{~s}^{-1}$ and 77 to $1000 \mathrm{~K}$ to capture the dynamic thermomechanical responses of commercial Ti64 alloy and (Khan, Kazmi et al. 2007) studied three different Ti64 alloys under compression at strain rates from $10^{-6}$ to $3378 \mathrm{~s}^{-1}$ and temperatures from 233 to $755 \mathrm{~K}$. Clearly, out of these three options, the study of (Nemat-Nasser, Guo et al. 2001) shows more proximity of the strain rate and temperature to the experimental machining conditions and this variant was therefore used in the rest of the demonstration made in the paper.

\subsubsection{Cuitino and Ortiz model of Ti6Al4V implemented in "AdvantEdge"}

AdvantEdge is an explicit time solver that calculates the dynamic equilibrium in time using a Lagrangian finite element formulation. The default material constitutive model implemented in the commercial software "AdvantEdge" for simulation of Ti6Al4V is based on a stress updating method, which can provide finite deformation range strainstress update algorithms at the kinematics level (Man, Ren et al. 2012). 
As per this model, the flow stress is defined as follows:

$$
\sigma(\alpha, \dot{\alpha}, T)=\mathrm{g}(\alpha) \theta(T) \Gamma(\dot{\alpha})
$$

where $g(\alpha), \theta(T)$ and $\Gamma(\dot{\alpha})$ refer to the isotropic strain hardening function, thermal softening and rate sensitivity respectively. The equations used to describe these three parts are shown in (8), (9) and (10).

$$
\begin{gathered}
G(\alpha)=\sigma_{0}\left(1+\frac{\alpha}{\alpha_{0}}\right)^{\frac{1}{N}} \\
\theta(T)=c_{0}+c_{1} T+\cdots+c_{5} T^{5} \\
\Gamma(\dot{\alpha})=\left(1+\frac{\dot{\alpha}}{\dot{\alpha}_{0}}\right)^{\frac{1}{M}}
\end{gathered}
$$

where $\sigma_{0}$ refers to the initial yield stress, $\alpha_{0}$ represents the reference strain and $\dot{\alpha}_{0}$ is reference strain rate.

\subsubsection{Tabulated flow stress model of Ti6Al4V implemented in "DEFORM"}

DEFORM is an Implicit solver employing the Newton Raphson technique. The default material model of Ti6Al4V used in DEFORM follows an equation $\bar{\sigma}=\bar{\sigma}(\bar{\varepsilon}, \dot{\varepsilon}, T)$, where $\bar{\sigma}, \bar{\varepsilon}, \dot{\varepsilon}$ and $\mathrm{T}$ refer to flow stress, equivalent plastic strain, equivalent plastic strain rate and temperature respectively. In order to reflect the true material behaviour of Ti6Al4V, the data of these parameters at several data point are fed using a tabular data format and a linear weighted average interpolation method is used to calculate the data at unknown points between existing flow stress data points. The stress-strain curve based on this tabulated model is shown in Fig. 1. 


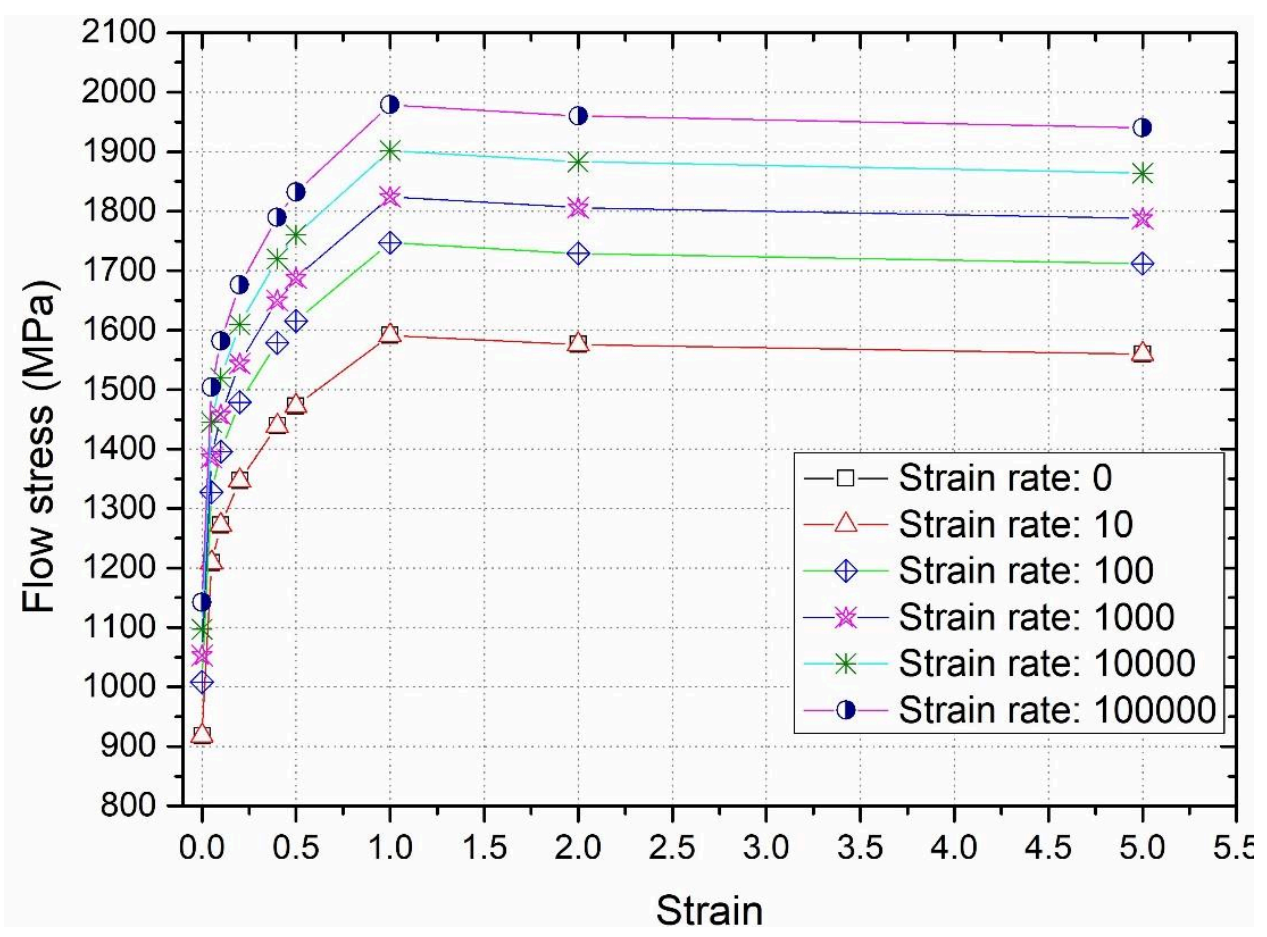

Fig. 1. Tabulated flow stress model of Ti6Al4V

\section{FEA methodology}

In order to perform the FEA simulation, a VUMAT code in Abaqus was developed so that each of the aforementioned material models can readily be described to study the material behaviour of Ti6Al4V. The idea was to first compare the VUMAT results against the standard results predicted by the software for a typical material model like the JC model, which is readily available in every software and thus, the VUMAT subroutine validity and reliability was established. The process to call the code in Abaqus followed the flowchart shown in Fig. 2. 


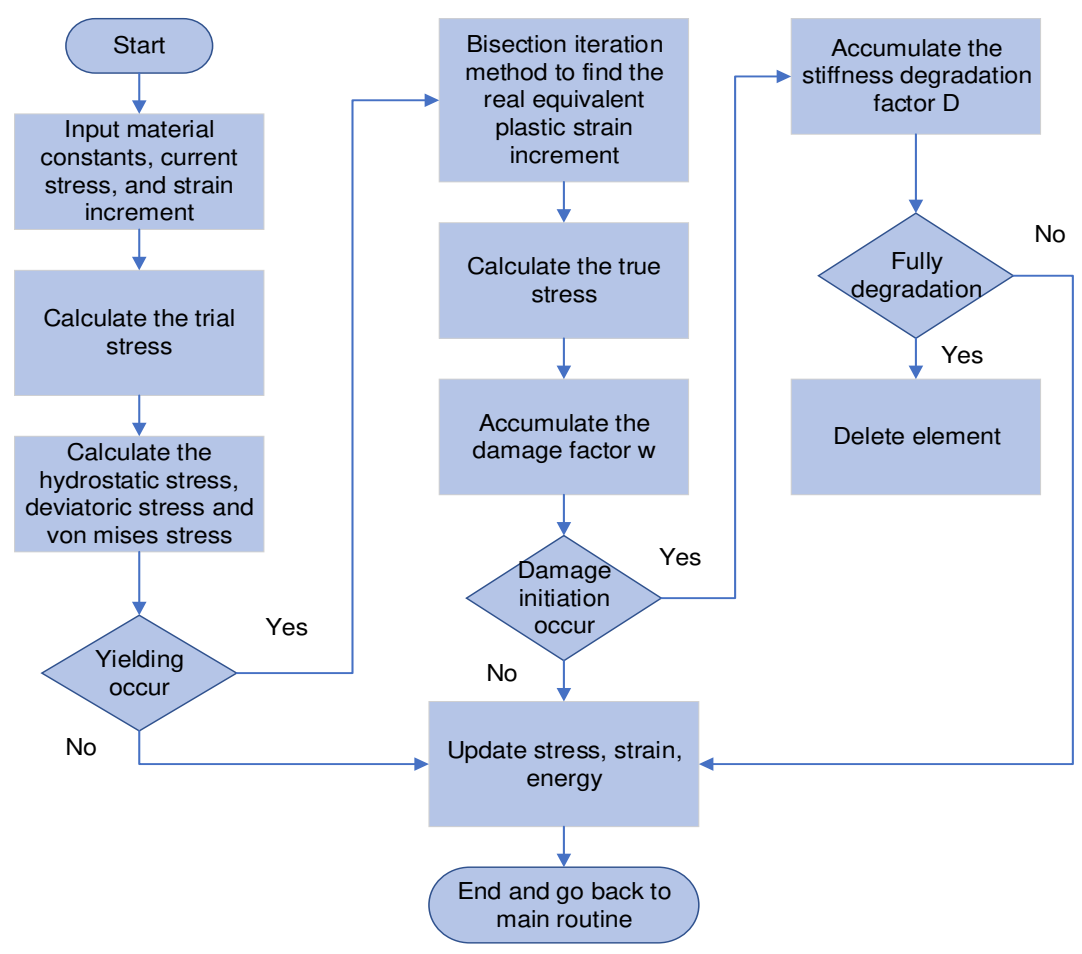

Fig. 2. Flowchart of calling VUMAT in Abaqus as implemented in this work

\subsection{Tensile testing}

\subsubsection{Testing considerations}

Prior to performing the FEA analysis on Ti6Al4V, we benchmarked our model by comparing uniaxial tensile test stress-strain plots using the same VUMAT sub-routine but merely by changing the parameters to be for silicon instead of Ti6Al4V. The same conditions and material constants were used to reproduce the strain-stress curve. This step helped us validate the results against the previously published paper by the authors of this paper (Goel, Llavori et al. 2018). It may be noted that the microscale and nanoscale properties are affected by the so called "size effect" and hence they cannot be extrapolated readily but the idea to simulate the nanoscale tensile test is merely to benchmark the model.

Accordingly, the work began by first performing the tensile test on silicon using the built-in JC model provided by Abaqus as a default choice and it was then compared with the tensile test of silicon using VUMAT code. The material properties used to 
perform the simulation on silicon are listed in Table 6 while the material constants used in the JC model are listed in Table 7.

Table 6 Material properties of silicon (Goel, Llavori et al. 2018)

\begin{tabular}{ccc}
\hline Density $\left(\mathrm{kg} / \mathrm{m}^{3}\right)$ & Poisson's ratio & Elastic modulus $(\mathrm{GPa})$ \\
\hline 2330 & 0.23 & 98 \\
\hline
\end{tabular}

Table 7 Constants used in JC model for silicon (Goel, Llavori et al. 2018)

\begin{tabular}{cccccccc}
\hline$A(\mathrm{MPa})$ & $B(\mathrm{MPa})$ & $N$ & $m$ & $C$ & $\dot{\varepsilon}_{0}\left(\mathrm{~s}^{-1}\right)$ & $T_{\text {room }}(\mathrm{K})$ & $T_{\text {melt }}(\mathrm{K})$ \\
\hline 896.394 & 529.273 & 0.3758 & 1 & 0.4242 & 1 & 293 & 1688 \\
\hline
\end{tabular}

\subsubsection{Boundary conditions and model development}

As for the tensile testing, a cylindrical workpiece of diameter $20.68 \mathrm{~nm}$ and length 48.98 nm was used to maintain the traceability with the literature (Goel, Llavori et al. 2018).

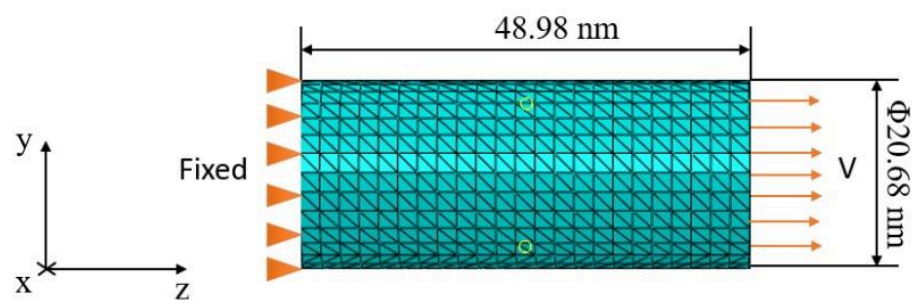

Fig. 3. FEA model of the workpiece

A 10-node modified quadratic tetrahedron $(\mathrm{C} 3 \mathrm{D} 10 \mathrm{M})$ element was used in this study and dynamic explicit analysis was chosen. As Fig.3 shows (on the left), the displacement in the $z$ direction was restricted and therefore the transverse contraction of the workpiece was allowed in both the $x$ and $y$ direction. On the right side, the velocity load was applied. In order to research the effect of different strain rates, the test strain rate was taken in the range of $1 \times 10^{-3} / \mathrm{ps}$ to $1 \times 10^{-5} / \mathrm{ps}$ according to the recent paper researching nanoscale tensile testing (Zhang, Han et al. 2007). The strain rate was converted into an equivalent velocity in order to define the appropriate boundary condition as follows: 
$\dot{\varepsilon}=\frac{\varepsilon}{\Delta t}=\frac{\Delta l}{l_{0} \Delta t}=\frac{v}{l_{0}}$

$v=l_{0} \times \dot{\varepsilon}=48.98 \times 10^{-6} \times 5 \times 10^{8}=24490 \mathrm{~mm} / \mathrm{s}$

where $v$ is equivalent velocity, $l_{0}$ is the initial length of the objective workpiece, $\Delta l$ is the change of length. When the length $l_{0}$ was taken as $48.98 \mathrm{~nm}\left(48.98 \times 10^{-9} \mathrm{~m}\right)$ and strain rate $\dot{\varepsilon}$ was taken as $0.0005 / \mathrm{ps}\left(5 \times 10^{8} \mathrm{~s}\right)$, a fixed velocity load $24490 \mathrm{~mm} / \mathrm{s}$ was applied on the workpiece during the simulation. A good overlap (shown in the later section) was found confirming reliability of the model.

Table 8 Material properties of Ti6Al4V (Gu, Dong et al. 2015)

\begin{tabular}{lll}
\hline Density $\left(\mathrm{kg} / \mathrm{m}^{3}\right)$ & Poisson's ratio & Elastic modulus $(\mathrm{GPa})$ \\
\hline 4430 & 0.33 & 110 \\
\hline
\end{tabular}

Table 9 Constants used in different models (Gu, Dong et al. 2015)

\begin{tabular}{|c|c|c|c|c|c|c|}
\hline Model & & & Parameter & & & Reference \\
\hline \multirow{4}{*}{$\mathrm{ZA}$} & $C_{l}$ & $C_{2}$ & $C_{3}$ & $C_{4}$ & $C_{5}$ & \multirow{4}{*}{$\begin{array}{c}\text { (KOTKUNDE } \\
\text { 2012) }\end{array}$} \\
\hline & 869.4 & 640.50 & 0.0013 & $-9.57 \times 10^{-4}$ & 0.0095 & \\
\hline & $C_{6}$ & $N$ & & & & \\
\hline & $6.94 \times 10^{-6}$ & 0.3867 & & & & \\
\hline \multirow{4}{*}{ VA } & $C_{l}(\mathrm{MPa})$ & $C_{2}(\mathrm{MPa})$ & $C_{3}$ & $C_{4}(\mathrm{MPa})$ & $C_{5}$ & \multirow{4}{*}{$\begin{array}{l}\text { (Tabei, Abed } \\
\text { et al. 2017) }\end{array}$} \\
\hline & 30 & 500 & 0.11 & 1400 & $4.2 \times 10^{-5}$ & \\
\hline & $C_{6}(\mathrm{MPa})$ & $C_{7}$ & $\dot{\varepsilon}_{p}^{* Y}$ & $\dot{\varepsilon}_{p}^{* H}$ & & \\
\hline & 1100 & 0.5 & $1.16 \times 10^{11}$ & $2.6 \times 10^{13}$ & & \\
\hline \multirow{4}{*}{ JC-1 } & $A(\mathrm{MPa})$ & $B(\mathrm{MPa})$ & $N$ & $m$ & $C$ & \multirow{4}{*}{$\begin{array}{c}\text { (KOTKUNDE } \\
\text { 2012) }\end{array}$} \\
\hline & 896.4 & 649.5 & 0.3867 & 0.7579 & 0.0093 & \\
\hline & $\dot{\varepsilon}_{0}\left(\mathrm{~s}^{-1}\right)$ & $T_{r e f}(\mathrm{~K})$ & $T_{m e l t}(\mathrm{~K})$ & & & \\
\hline & 1 & 323 & 1923 & & & \\
\hline \multirow{4}{*}{ JC-2 } & $A(\mathrm{MPa})$ & $B(\mathrm{MPa})$ & $N$ & $m$ & $C$ & \multirow{4}{*}{$\begin{array}{l}\text { (Gu, Dong et } \\
\text { al. 2015) }\end{array}$} \\
\hline & 1098 & 1092 & 0.93 & 1.1 & 0.014 & \\
\hline & $\dot{\varepsilon}_{0}\left(\mathrm{~s}^{-1}\right)$ & $T_{r e f}(\mathrm{~K})$ & $T_{m e l t}(\mathrm{~K})$ & & & \\
\hline & 1 & 298 & 1878 & & & \\
\hline
\end{tabular}

After performing a satisfactory comparison for silicon, the material description was changed from silicon to Ti6Al4V and this way a well calibrated tensile testing model 
was obtained for Ti6Al4V. We then performed the predictive work via this model to compare the different material models under uniaxial stress conditions as well as to probe the influence of the strain rate effects on the resulting stress-strain plots. The material properties and other constants used to perform the tensile test simulation on Ti6Al4V using JC, ZA and VA models are shown in Table 8 and Table 9.

\subsubsection{Geometric consideration for cutting model development}

The geometry of the tool used is shown in Fig. 4 and the workpiece size used was a 10 $\mathrm{mm} \times 4 \mathrm{~mm}$.

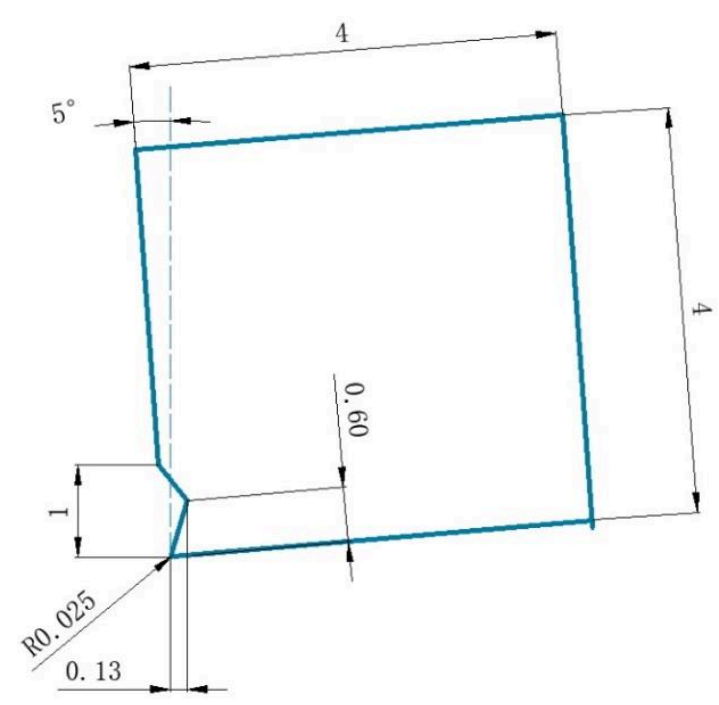

Fig. 4. The geometry of tool (unit: $\mathrm{mm}$ )

Fig. 5 shows the schematic illustration of the feed, surface speed and geometry of tool and workpiece used during the simulations while the orthogonal 2D machining parameters used during the simulations are listed in Table 10. The machining process assumed dry conditions and the boundary conditions used were as shown in Fig. 6, both DEFORM and AdvantEdge defines them in the same way. Usually, in turning of a workpiece represented in a $2 \mathrm{D}$ presentation, the surface speed refers to linear cutting speed of the workpiece, the feed refers to the uncut chip thickness. 


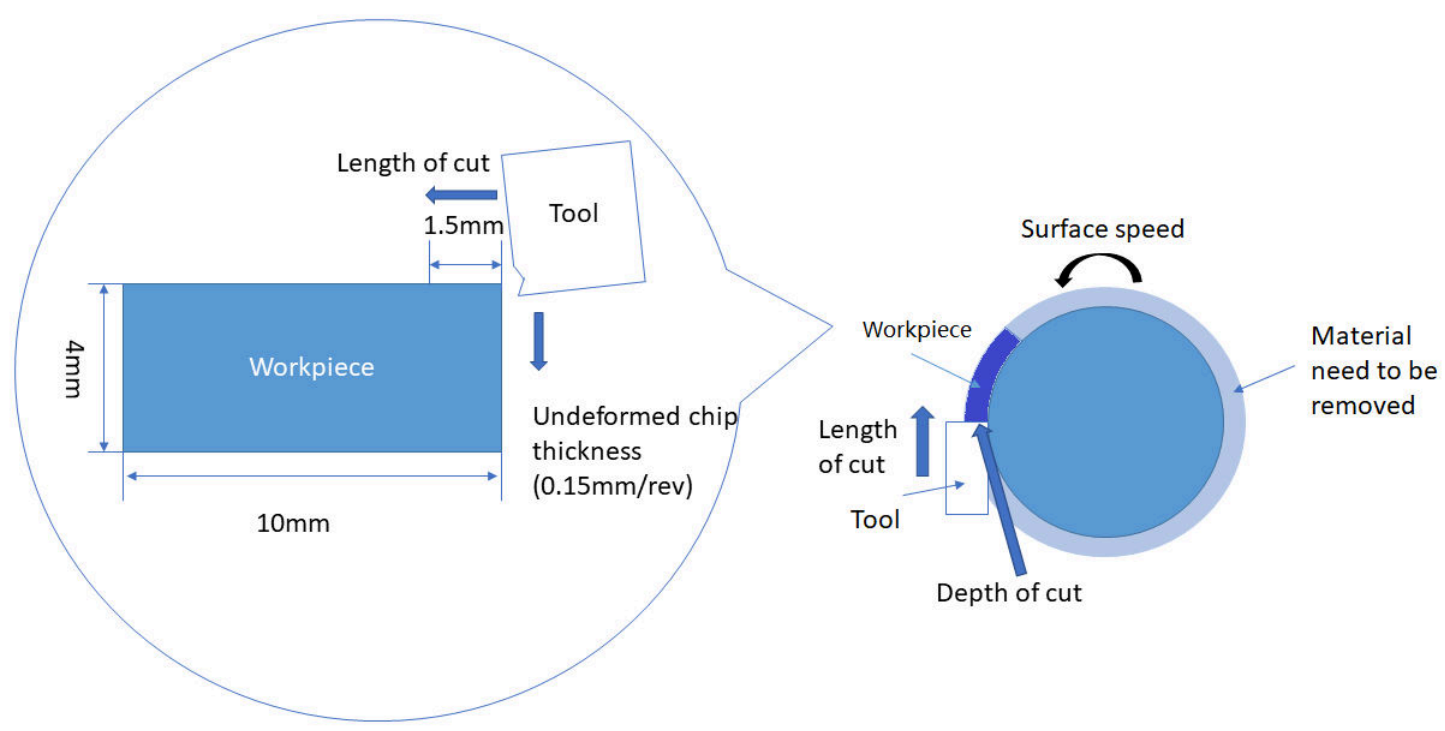

Fig. 5. The illustration of cutting parameters and geometry of workpiece

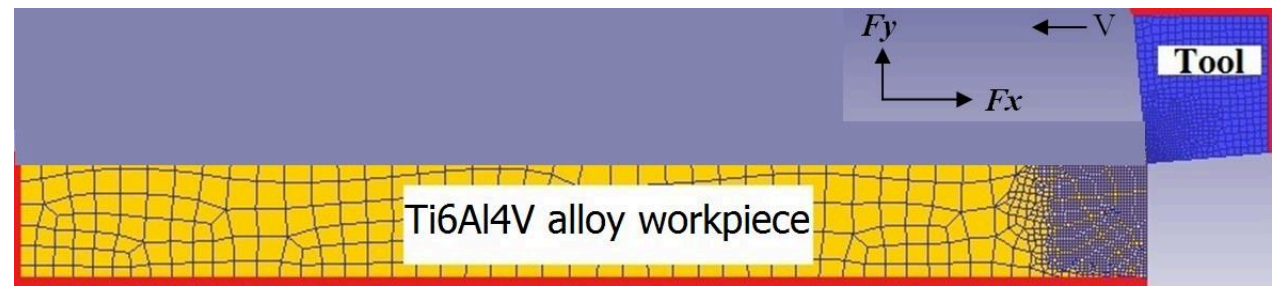

Fig. 6. Schematic illustration of the forces acting on the tool during cutting

Table 10 Cutting parameters in dry conditions

\begin{tabular}{cccc}
\hline Parameter & Value & Parameter & Value \\
\hline Surface speed & $45(\mathrm{~m} / \mathrm{min})$ & Width of cut & $\begin{array}{c}\text { Plane stress } \\
\text { condition }\end{array}$ \\
Undeformed chip thickness & $0.15(\mathrm{~mm} / \mathrm{rev})$ & $\begin{array}{c}\text { Length of cut } \\
\text { Environment } \\
\text { temperature }\end{array}$ & $1.5(\mathrm{~mm})$ \\
Heat transfer coefficient & $11\left(\mathrm{~N} / \mathrm{sec} / \mathrm{mm} /{ }^{\circ} \mathrm{C}\right)$ & $20\left({ }^{\circ} \mathrm{C}\right)$ \\
Shear friction factor & 0.3 & & \\
\hline
\end{tabular}

\section{Results and discussions}

\subsection{Tensile testing on silicon}

In order to test the accuracy of the VUMAT sub-routine developed in this work, simulations were performed to compare the 2D, 3D (by default model) and 3D (by VUMAT sub-routine models) at two different strain rates of $0.005 / \mathrm{ps}$ and $0.0005 / \mathrm{ps}$.

The comparison results are shown in Fig. 7 and Fig. 8. An excellent overlap suggests 
that the developed VUMAT worked well on silicon and thus became the basis for testing various material models of Ti6Al4V in the next section.

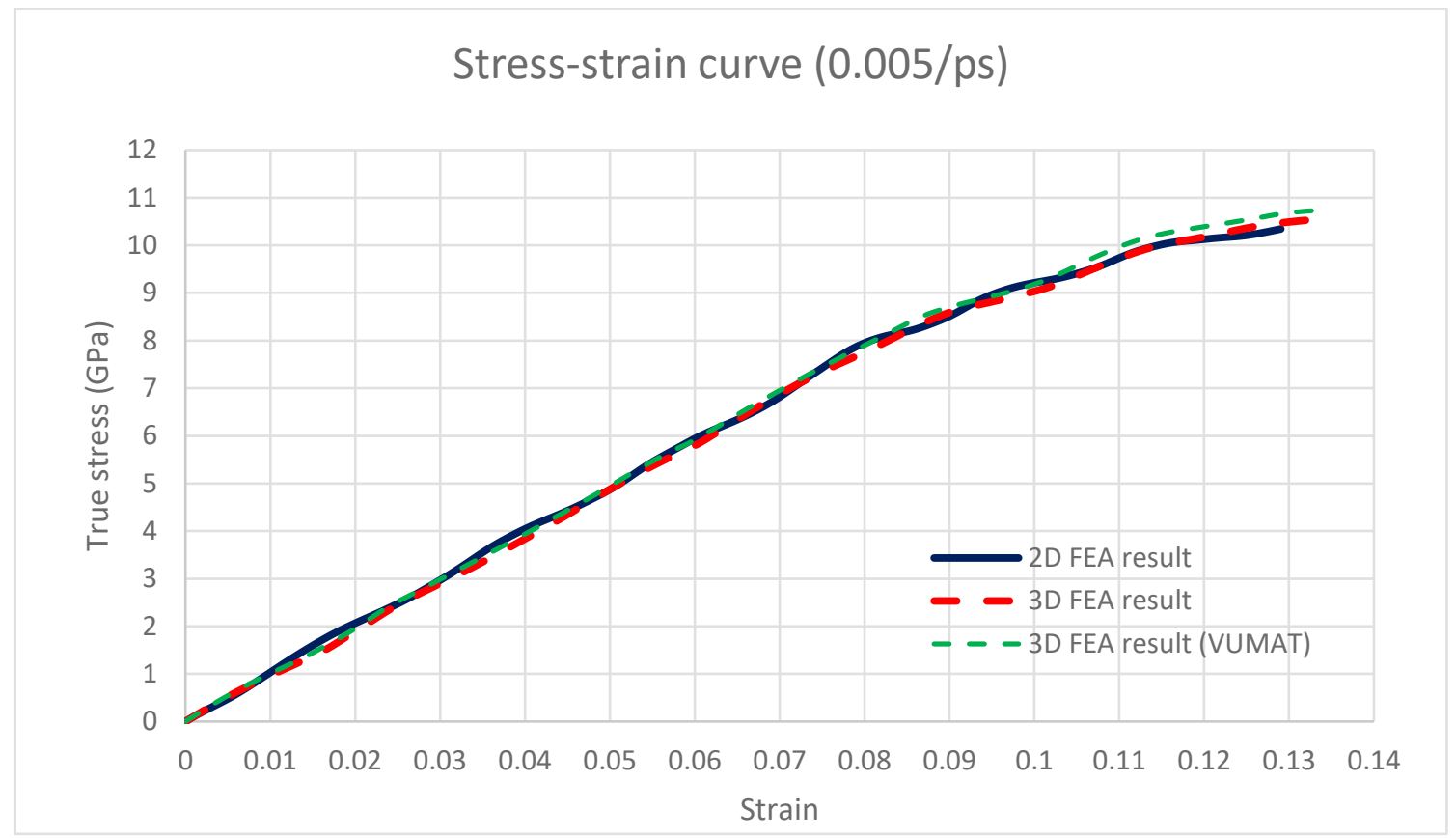

Fig. 7. Comparison between built-in model and VUMAT subroutine $(0.005 / \mathrm{ps})$

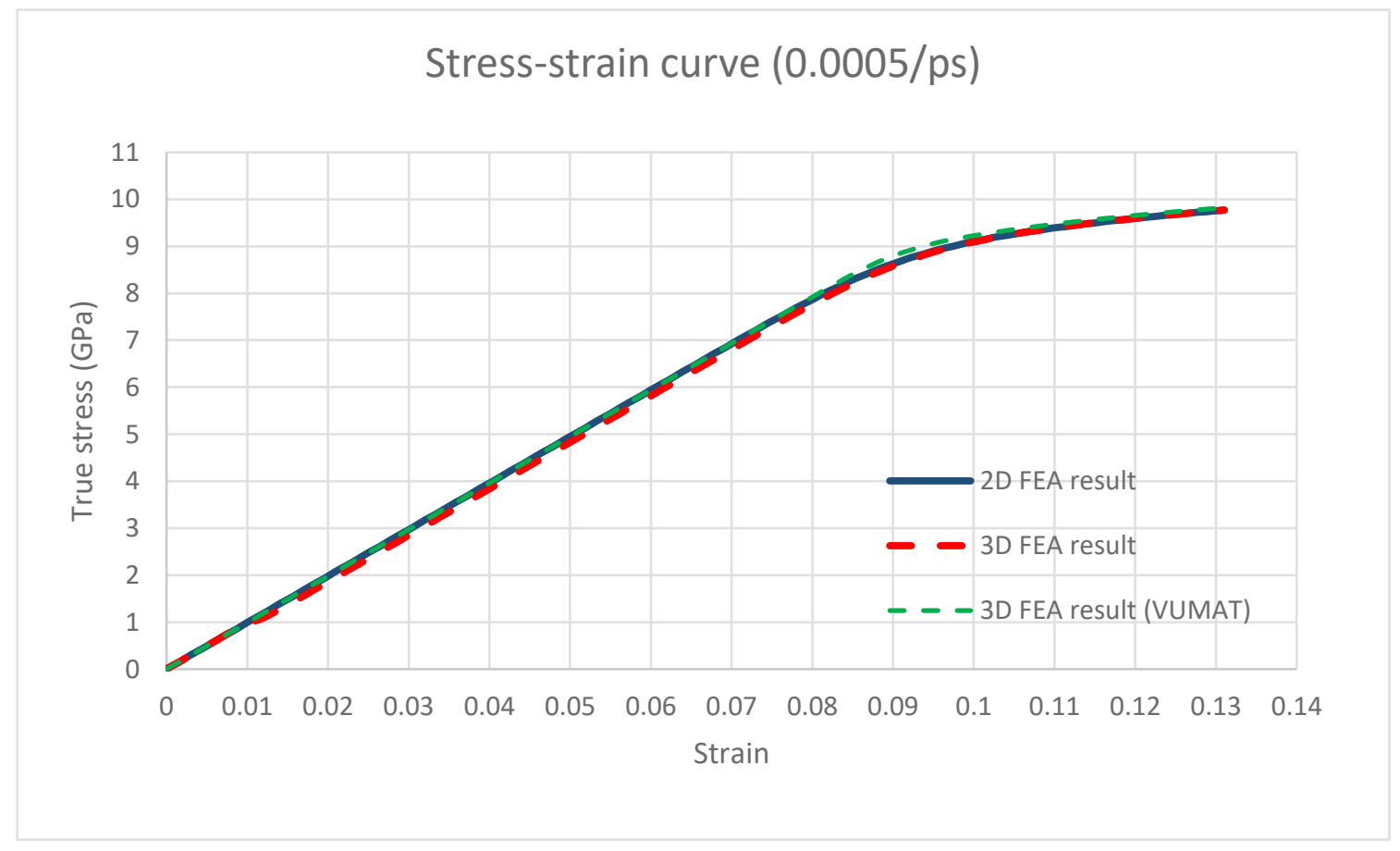

Fig. 8. Comparison between built-in model and VUMAT subroutine (0.0005/ps) 


\subsection{Tensile testing to compare different material constitutive models of Ti6Al4V}

Now that the VUMAT sub-routine is well tested and calibrated both for silicon and Ti6Al4V and was found to work well at different strain rates, the three material models namely JC, ZA and VA model, were tested under the same tensile test conditions but at a different strain rate of $0.0005 / \mathrm{ps}$. The differences predicted by the models are shown in Fig. 9.

It may be noted that the Cuitino and Ortiz model could not be compared during tensile testing due to proprietary information (parameters were not made available by AdvantEdge) and thus only cutting test results are available from the Cuitino and Ortiz model discussed in later sections.

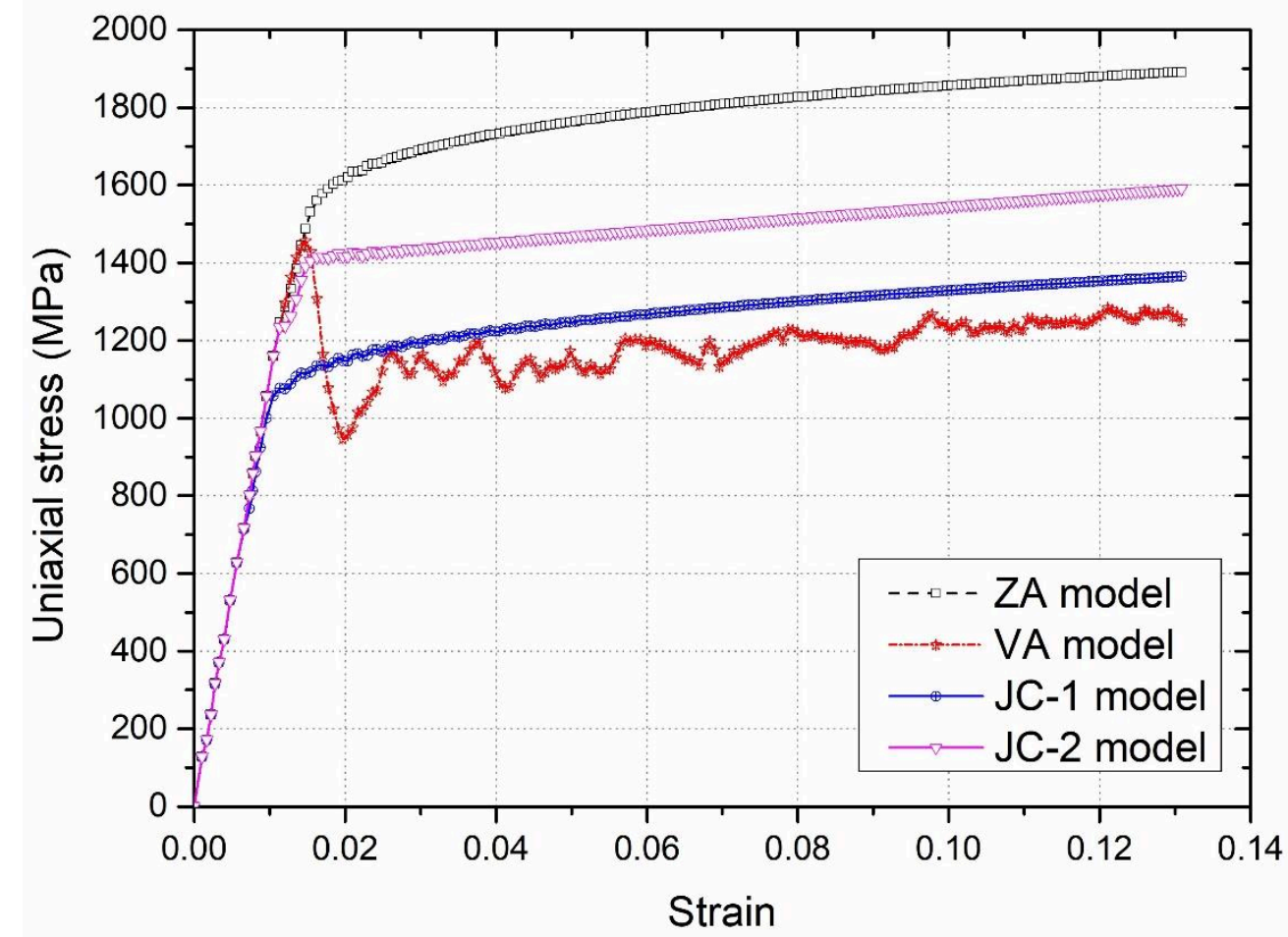

Fig. 9. Uniaxial stress-strain curve of Ti6Al4V predicted by various material constitutive models

From Fig. 9, it may be observed that the material behaviour of Ti6Al4V was predicted differently by each of the material constitutive models. By looking at this graph, it is hard to say which behaviour is most reliable as the material samples differ (even experimental samples will differ due to the presence of residual stress depending on the 
processing history) but Fig. 9 mainly highlights the extent of differences between these various material models. The nanoscale yield stress of Ti6Al4V, revealed by the ZA, VA, JC-1, JC-2 models were 1531.03 MPa, 1455.71 MPa, 1077.55 MPa, 1234.54 MPa respectively. The variations in the subsequent plastic behaviour are well evident. One may note here that the JC-2 model was developed at room temperature $\left(25^{\circ} \mathrm{C}\right)$ while the JC-1 model was developed at a slightly higher temperature $\left(50^{\circ} \mathrm{C}\right)$. Interestingly, the VA model showed more noise whilst the other three models provided a smoother plot.

\subsection{Tensile testing on Ti6Al4V at different strain rates using JC-2 model}

This section shows the effect of strain rate on Ti6Al4V using JC-2 model while varying the strain rates between $0.001 / \mathrm{ps}$, to $0.00001 / \mathrm{ps}$ (see fig 10). At higher strain rates, the value of stress was observed to be higher. It signified that the strain rate has a marked influence on the plastic response of Ti6Al4V especially in the deformation zone i.e. higher strain rate was accompanied by an increase in the strain energy absorbed by Ti6Al4V before rupture. The slope of the linear curve in the elastic regime refers to elastic modulus of the material, here obtained as $110 \mathrm{GPa}$ for Ti6Al4V.

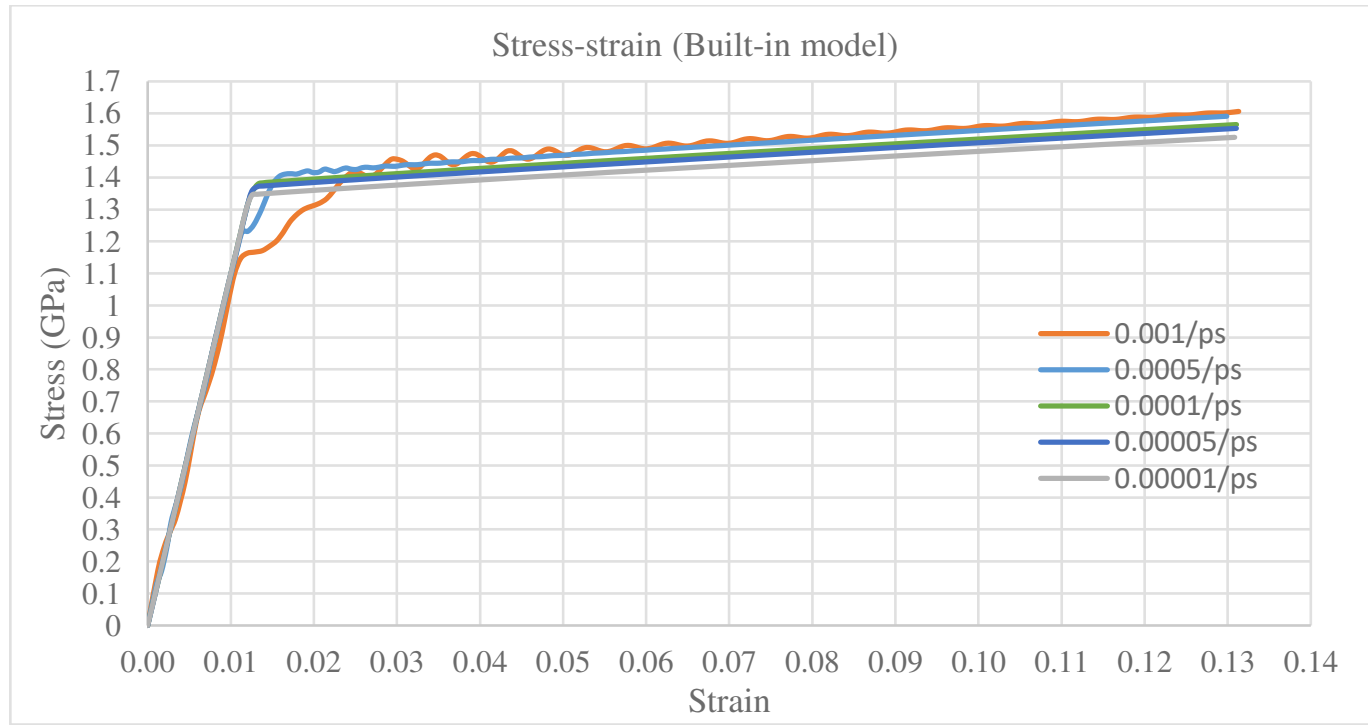

Fig. 10. The influence of strain rate on the uniaxial stress-strain behaviour of Ti6Al4V 


\subsection{Cutting test simulations}

\subsubsection{Stress and temperature}

A snapshot captured from the cutting simulations of Ti6Al4V while using the same cutting parameters but different material constitutive equations, namely the tabulated stress model (used as benchmark) compared with the JC-1, JC-2, ZA and Cuitino and Ortiz models (obtained from AdvantEdge) - see Fig 11 to Fig 15. These cutting simulations assumed an uncoated carbide cutting tool to investigate stress and temperature in the cutting zone during the machining process.

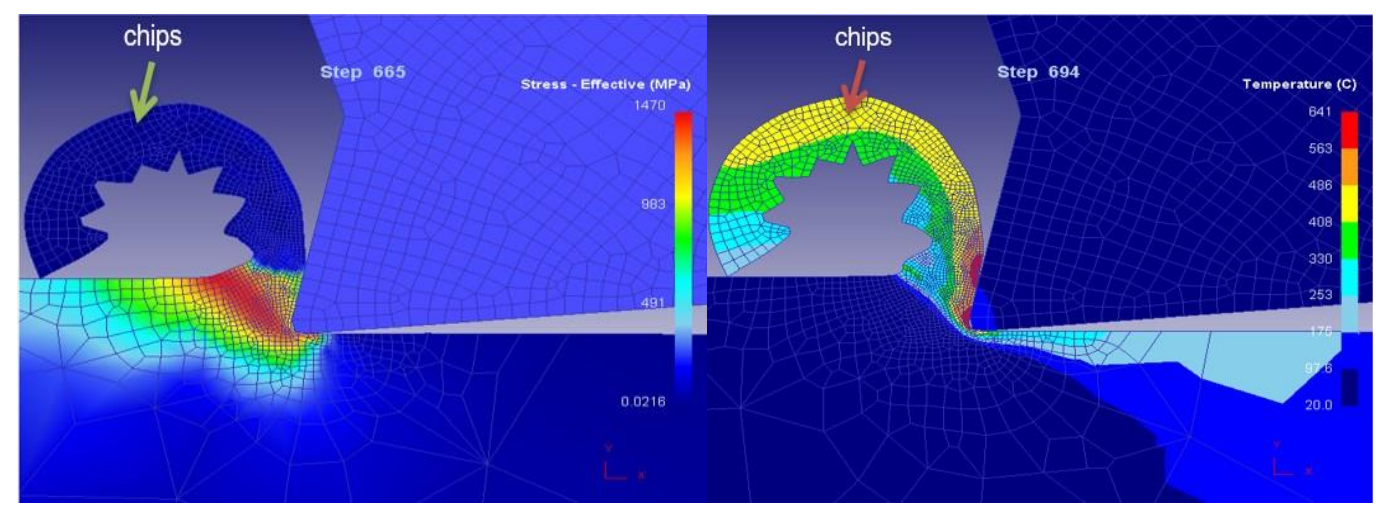

Fig. 11. The effective stress and temperature during machining process obtained from DEFORM using tabulated stress model (benchmark)

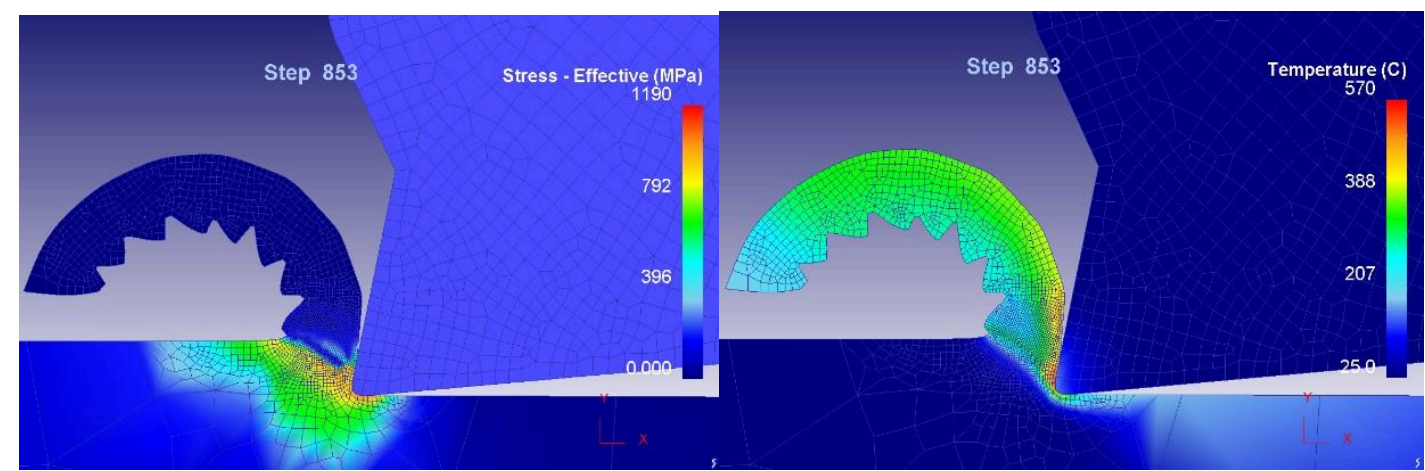

Fig. 12. The effective stress and temperature obtained from DEFORM using JC-1 model 


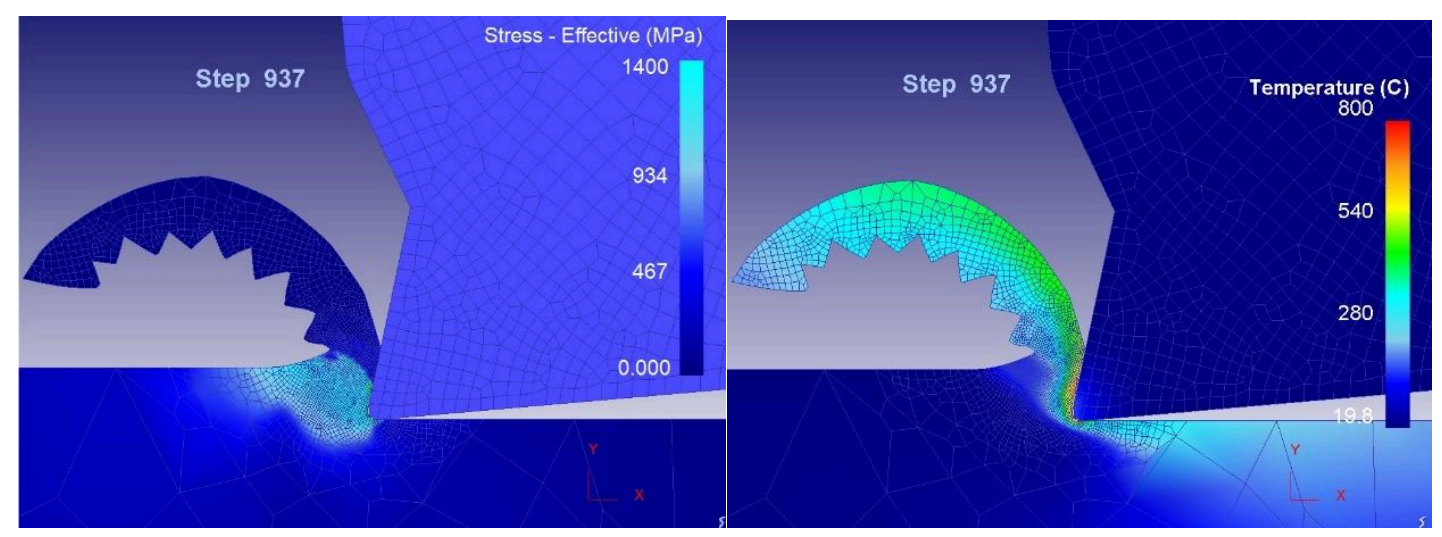

Fig. 13.The effective stress and temperature obtained from DEFORM using JC-2 model

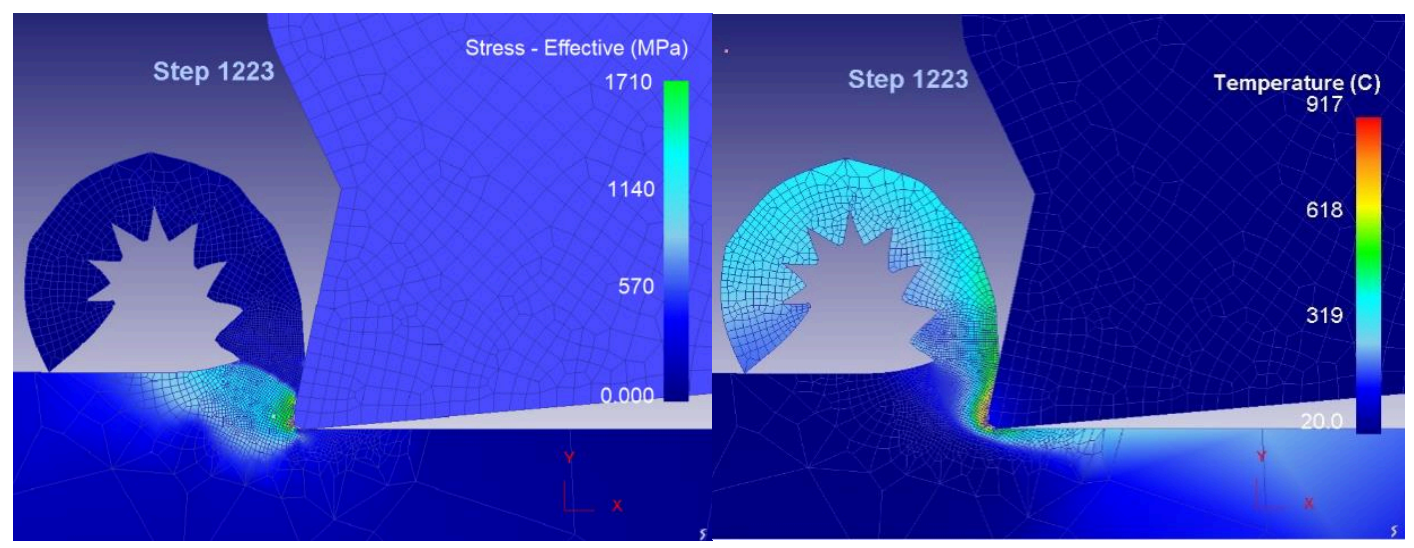

Fig. 14. The effective stress and temperature obtained from DEFORM using ZA model

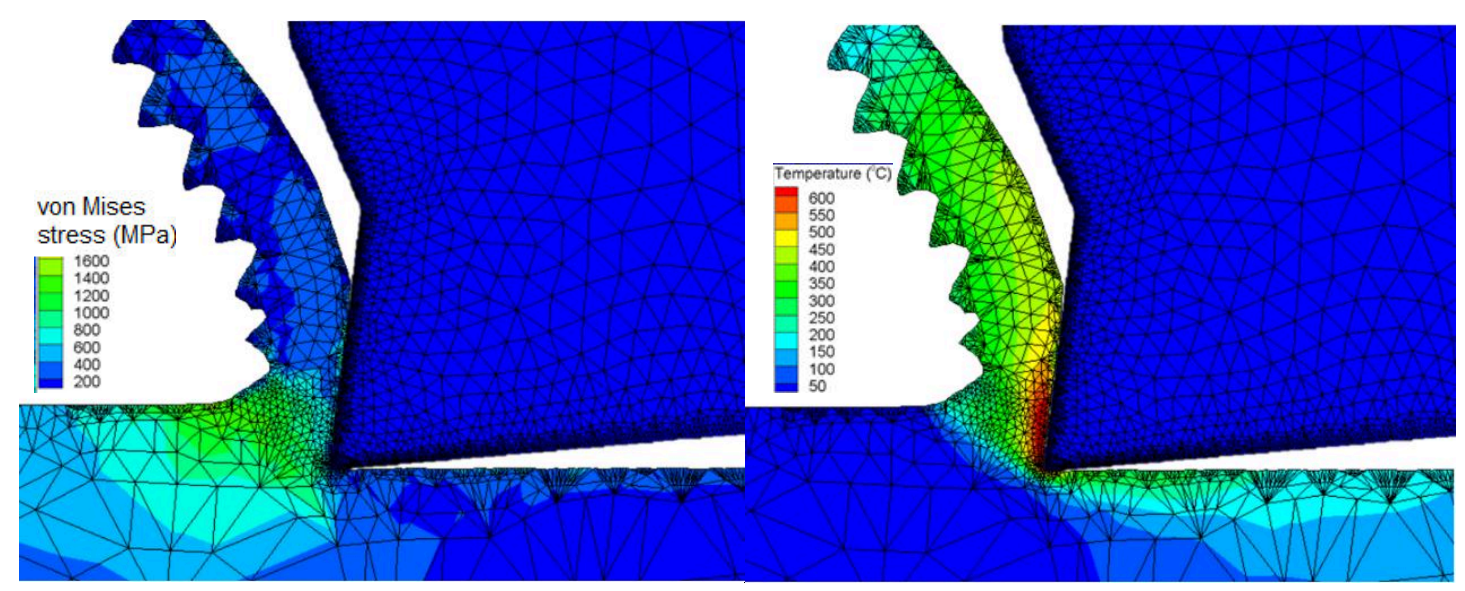

Fig. 15. The effective stress and temperature obtained from AdvantEdge using Cuitino and Ortiz model 
Table 11 Summary of cutting results showing stress and temperature peak in the cutting zone of Ti6Al4V obtained from the simulations

\begin{tabular}{ccc}
\hline Material model name & $\begin{array}{c}\text { Peak stress (MPa) in the cutting } \\
\text { zone of Ti6Al4V }\end{array}$ & $\begin{array}{c}\text { Peak temperature }\left({ }^{\circ} \mathrm{C}\right) \text { in the } \\
\text { cutting zone of Ti6Al4V }\end{array}$ \\
\hline $\begin{array}{c}\text { Tabulated stress model } \\
\text { (Benchmark) }\end{array}$ & 1470 & 641 \\
JC-1 & 1190 & 570 \\
JC-2 & 1400 & 800 \\
ZA model & 1710 & 917 \\
$\begin{array}{c}\text { Cuitino and Ortiz model } \\
\text { (obtained from AdvantEdge) }\end{array}$ & 1600 & 600 \\
\hline
\end{tabular}

A summary of the results obtained from different models highlighting peak stress and temperature is provided in Table 11. Similar to the observations noted from the uniaxial stress test, the peak von Mises stress in the cutting zone of Ti6Al4V was seen as consistent with the peak uniaxial stress. Most of these results suggest that the ZA model predicts the peak temperature and peak temperature in the cutting zone as much higher than the predictions made by the other models, while the JC-1 model underestimates these. In general, the peak maximum stress during cutting of Ti6Al4V was about 1470 MPa while the peak machining temperature in the cutting zone was of the order of 600 ${ }^{\circ} \mathrm{C}$.

The chip morphology observed in the simulations showed the Saw-tooth chip characteristic which is unique to Ti6Al4V and many reports are published in the literature verifying the simulation based observations reported in this work (Gente, Hoffmeister et al. 2001, Hua and Shivpuri 2004, Calamaz, Coupard et al. 2008). The cutting chips are widely recognised as being the fingerprint of the metal machining process and are broadly classified in two categories: steady state continuous chips and cyclic chips (Saw-tooth chips are one kind of cyclic chip) (Vyas and Shaw 1999). Extant literature on the formation of Saw-tooth chips (as evidenced by the FEA simulations in this work while cutting Ti6Al4V) proposes two broad theories (i) 
adiabatic shear theory and (ii) cyclic crack theory (Calamaz, Coupard et al. 2011). A new theory combining both of these was also proposed and Saw-tooth chip formation is said to be due to adiabatic shear sensitivity of the material i.e. Saw-tooth chips of sensitive materials are formed due to thermoplastic instability whereas chips of insensitive materials are formed due to crack initiation and propagation (Upadhyay, Jain et al.). The chip morphology could be affected by many factors, such as cutting parameters, mechanical properties ( $\mathrm{Fu}$, Chen et al. 2017), and material constitutive models. The cutting speed and feed rate had the opposite effect on Saw-tooth chip morphology. While an increase in cutting speed reduces the peak height of Saw-tooth chips, a higher feed rate increases this peak height (Bai, Sun et al. 2017). The material constitutive models influence thermoplastic shear as well as the hot mechanical properties. From the results shown in Table 11, it may be seen that high temperature is accompanied by an increased cutting force indicating that work hardening is less influential at temperatures around $900{ }^{\circ} \mathrm{C}$. Meanwhile, when plastic strain reached a critical value, a shear band was formed and the chip segmentation occurred, so the periodic shear bands were observed in the FEA to be due to the periodic nature of this cycle resulting in the Saw-tooth chip-formation process, causing fluctuations in the force curve (Bai, Sun et al. 2017).

\subsubsection{Variation in the forces during cutting}

The simulation results were used to extract the cutting forces in the two principal directions, $F_{c}$ or $F_{x}$ acting in the $X$ direction (shown earlier in Figure 6) referred to as axial cutting force or feed force in machining context or a friction force during a normal scratch test whilst $F_{t}$ or acts in the $Y$ direction referred to as tangential cutting force or thrust force in machining and as normal force in the scratching literature. The ratio of $\mathrm{Fx} / \mathrm{Fy}$ (friction force/normal force) during cutting is referred to as "coefficient of kinetic 
friction" (COF) and is a useful indicator to compare simulation against experiments (Goel, Stukowski et al. 2013). A comparison of results obtained for $F_{x}$ and $F_{y}$ is shown in Fig. 16 and Fig. 17. As it may be seen, the JC-2 model showed the closest proximity with the tabulated stress model in comparison to the JC-1 model. Also, the Cuitino and Ortiz model results extracted from AdvantEdge showed wide fluctuations and larger values of forces compared to the other three models. It is obvious that the forces are much higher in the case of AdvantEdge.

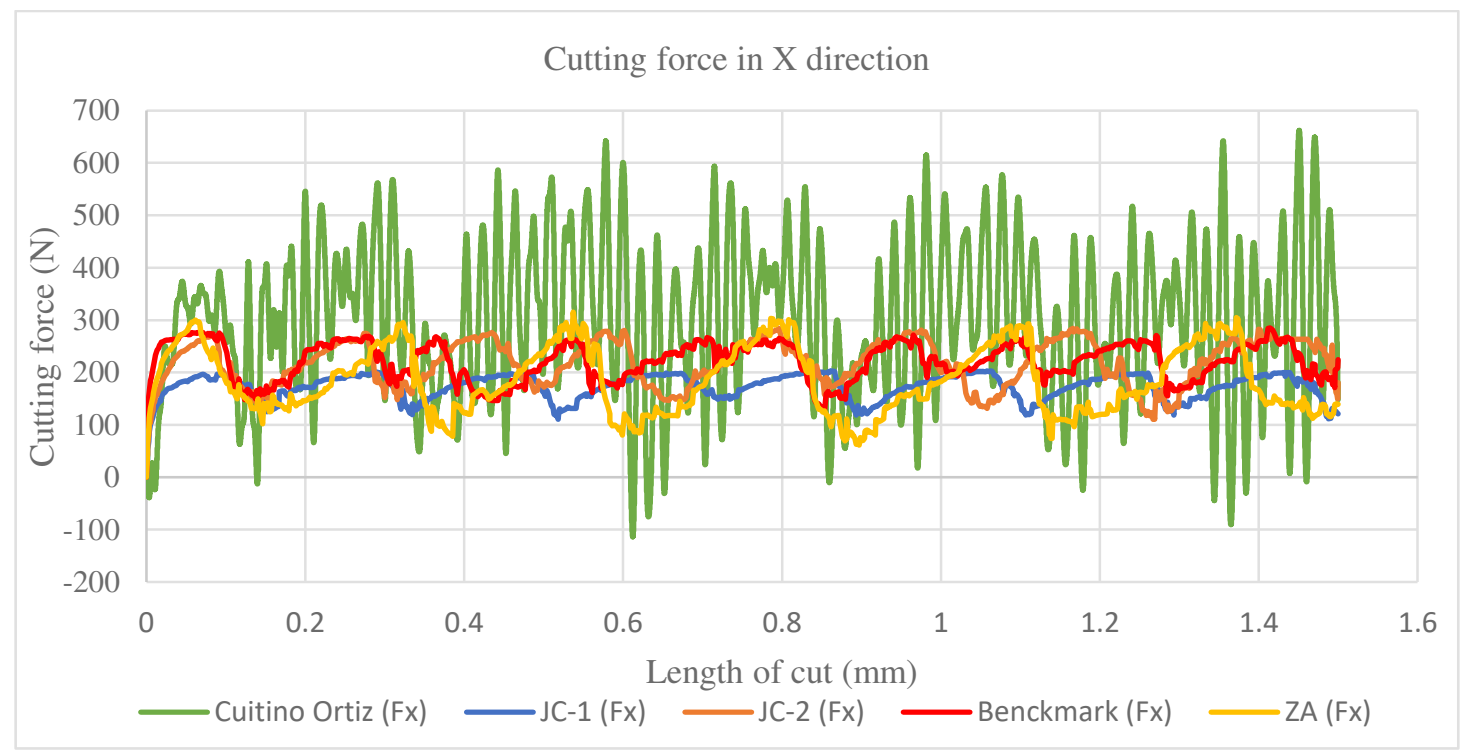

Fig. 16. Comparison of cutting force in $x$ direction

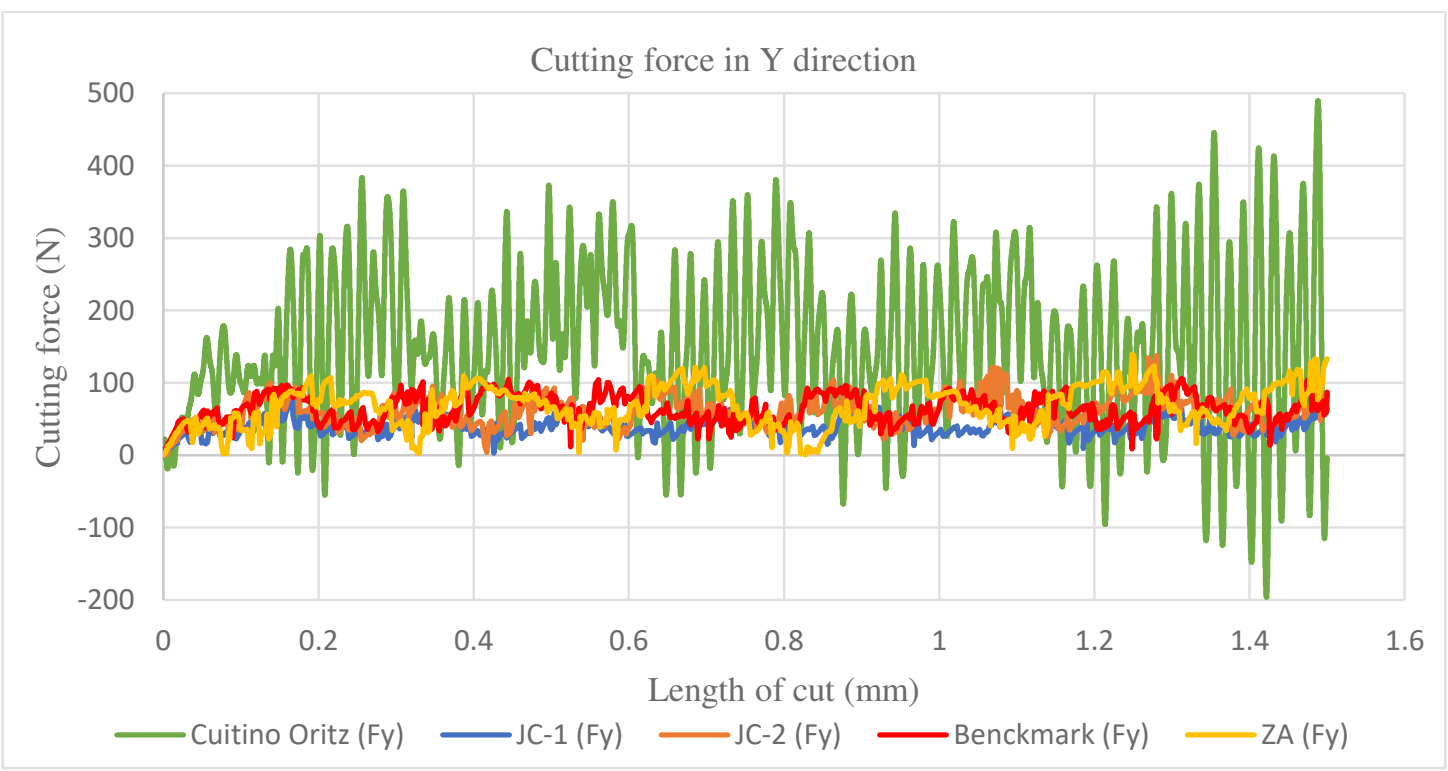

Fig. 17. Comparison of cutting force in $y$ direction 
Table 12 Simulation results comparing various material models tested in this work

\begin{tabular}{ccccccc}
\hline $\begin{array}{c}\text { Material } \\
\text { Model }\end{array}$ & $\begin{array}{c}\text { Friction } \\
\text { force }\left(F_{x}\right) \\
(\mathrm{N})\end{array}$ & $\begin{array}{c}\text { Percentage } \\
\text { difference } \\
(\%)\end{array}$ & $\begin{array}{c}\text { Thrust } \\
\text { force }\left(F_{y}\right) \\
(\mathrm{N})\end{array}$ & $\begin{array}{c}\text { Percentage } \\
\text { difference } \\
(\%)\end{array}$ & $\begin{array}{c}\text { COF } \\
\left(F_{x} / F_{y}\right)\end{array}$ & $\begin{array}{c}\text { Percentage } \\
\text { difference } \\
(\%)\end{array}$ \\
\hline $\begin{array}{c}\text { Tabulated } \\
\text { flow stress }\end{array}$ & 219.1486 & & 64.3060 & & 3.4079 & \\
$\begin{array}{c}\text { (Benchmark) } \\
\text { JC-1 }\end{array}$ & 166.7175 & 23.9 & 42.9255 & 33.2 & 3.8839 & -14.0 \\
JC-2 & 212.875 & $\mathbf{2 . 9}$ & 62.5376 & $\mathbf{2 . 8}$ & 3.4040 & $\mathbf{0 . 1}$ \\
ZA & 185.4594 & 15.4 & 66.6738 & -3.7 & 2.7816 & 18.4 \\
Cuitino Ortiz & 298.812 & -36.4 & 150.147 & -133.5 & 1.9901 & 41.6 \\
\hline
\end{tabular}

A summary of these results is presented in Table 12 showing quantitative differences in the forces revealed by the material models. At this point, it becomes an intellectual curiosity to survey the literature to see how the values of COF obtained from the simulations in this work compare with the literature. In that spirit, several papers were reviewed from the literature which have looked at machining Ti6Al4V both using simulations and experiments and the values of COF were extracted to compare with the current simulations shown in Figure 18.

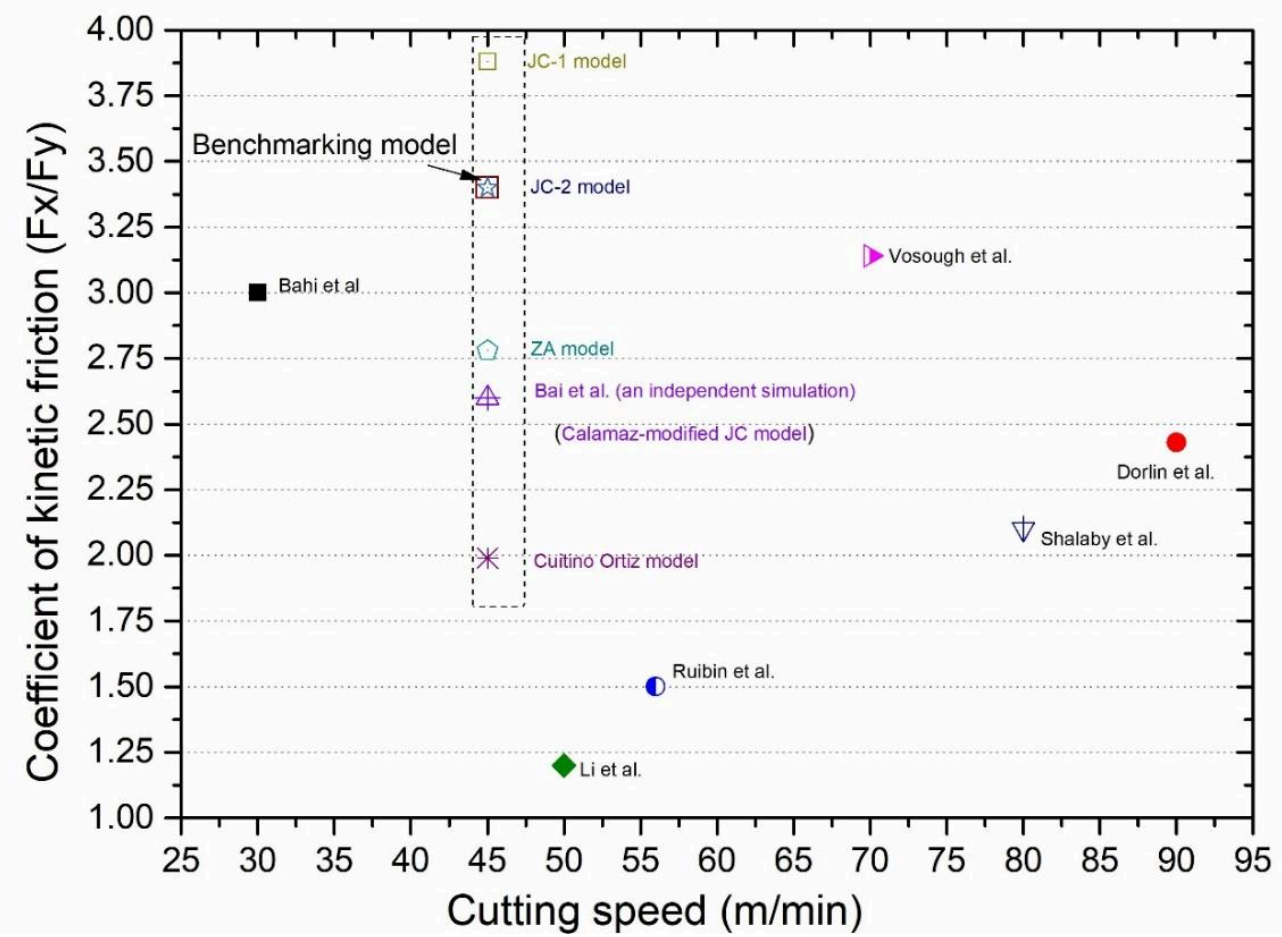

Figure 18: Comparison of simulation wise obtained values of COF against the surveyed wealth of literature reporting various values of $\mathrm{COF}$ as a function of cutting speed 
In preparation of Figure 18 the works reviewed were that of (Dorlin, Fromentin et al. 2016), (Bahi, List et al. 2016), (Bai, Sun et al. 2017), (Li, Qiu et al. 2016), (Ruibin and Wu 2016), (Shalaby and Veldhuis 2018) and (Vosough, Schultheiss et al. 2013). There are a number of other works reported on machining Ti6Al4V but we draw this brief comparison merely for the purpose of comparing the results we obtained from our models rather than consolidating the entire series of experimental trials performed on Ti6Al4V to date. From Figure 18, it is evident that the COF during machining of Ti6Al4V is larger than unity i.e. friction force is higher than the thrust force. It was, however, not immediately clear from this comparison to say which model makes the best prediction. We however note that the work of (Vosough, Schultheiss et al. 2013) has an inherent advantage for comparing the results reported in the simulation study presented here. They compared their experimental results readily against the JC model and obtained very close proximity between their simulations and experiments. It alluded to the fact that the proposed benchmarked tabulated stress model and the JC-2 model performed fairly consistently with their reported experimental results.

\subsection{Comparison of peak stress during tensile testing and during cutting}

As a final step, a comparison was made to examine the peak stress obtained from the tensile test and von Mises equivalent stress obtained during machining (see Table 13). This comparison shows that the von Mises flow (deviatoric strain energy or J2 theory) criterion in a ductile metal like Ti6Al4V follows the uniaxial stress consistently across all the material models tested in the work. Also, if the tabulated material model is to be considered as a good benchmark then the JC-2 model seems to be a more consistent model in predicting the material response of Ti6Al4V under a wide variety of stress behaviours during tribology, wear, machining and other contact loading conditions. This observation is also supported by the work of (Vosough, Schultheiss et al. 2013) 
who have validated the JC-2 model for a wide range of uncut chip thicknesses with their experiments on Ti alloy.

Table 13 Comparison of flow stress of different testing with different models

\begin{tabular}{ccccc}
\hline \multirow{2}{*}{ Model } & \multicolumn{2}{c}{ Tensile testing } & \multicolumn{2}{c}{ Cutting } \\
\cline { 2 - 5 } & $\begin{array}{c}\text { Uniaxial (true) } \\
\text { stress (MPa) }\end{array}$ & $\begin{array}{c}\text { Percentage } \\
\text { difference }(\%)\end{array}$ & $\begin{array}{c}\text { von Mises stress } \\
(\mathrm{MPa})\end{array}$ & $\begin{array}{c}\text { Percentage } \\
\text { difference }(\%)\end{array}$ \\
\hline $\begin{array}{c}\text { Tabulated flow } \\
\text { stress model of }\end{array}$ & $/$ & $/$ & 1470 & 0 \\
Deform & 1180 & 19.7 & 1190 & 19.0 \\
JC-1 model & 1420 & $\mathbf{3 . 4}$ & 1400 & $\mathbf{4 . 8}$ \\
JC-2 model & 1670 & -13.6 & 1710 & -16.3 \\
ZA model & & & 1600 & -8.8 \\
Cuitino Ortiz & & & & \\
\hline
\end{tabular}

\section{Conclusions}

This paper aims to elucidate quantifiable differences between a wide range of material constitutive models available for simulation of the important biomaterial and aerospace material Ti6Al4V. In the past, more than a dozen material models have been proposed (e.g. the Arrhenius-Type model, the Field-Backofen model, the Khan-Huang-Liang model, the Mechanical Threshold Stress model, the Johnson-Cook model, the MultiBranch model, the Tangent hyperbolic model, the Voyiadjis-Abed model, the ZerilliArmstrong (ZA) model, the Baker Modification of the EI-Magd model, the Cuitino and Ortiz model and the tabulated material model) to perform finite element analysis of contact loading simulations on Ti6Al4V alloys. Several of these material models are widely used and implemented commercially, such as the Johnson-cook model, tabulated flow stress model and ZA model.

Taking the examples of a uniaxial tensile test and cutting tests, these models were compared to draw a quantifiable comparison. This study in its present form will help researchers in addressing more specific engineering issues like wear, tribology and 
contact loading which are critical for delicate biomedical applications. From the various simulation test cases performed and reported in this study, the following may be concluded:

(i) Strain rate has a marked influence on the plastic response of Ti6Al4V especially in the deformation zone i.e. within the range of strain rates tested, higher strain rate was accompanied by an increase in the strain energy absorbed by Ti6Al4V before rupture.

(ii) Across various material models reported in the literature, one variant of the Johnson-Cook model seems to provide the most consistent values for the uniaxial tensile simulations and scratch tests. As is known for macroscopic cutting, the friction force $\left(F_{x}\right)$ was observed to be higher than the normal force $\left(F_{y}\right)$ during cutting of Ti6Al4V. The coefficient of kinetic friction reported in the literature during various cutting tests varies so widely that makes it difficult to say which particular material model will be the best for a given material. However, the results compared to the tabulated flow stress model used as a benchmark showed a proximity within an error of $5 \%$ in predicting the peak von Mises stress and cutting forces obtained from the JC2 model as opposed to other material models that showed variations beyond $40 \%$ in the cutting force predictions and up to $20 \%$ in estimating the peak stress in the cutting zone.

(iii) All material models revealed the phenomenon of Saw-tooth kind of chips being the characteristic feature of Ti6Al4V deformation during scratching. Moreover, the instantaneous change in the friction force reflected the process of chip formation i.e. an increase in the friction force reflected the deformation occurring in the area of contact between the cutter's attack angle causing a shear slip when the stress reached beyond a threshold value. The cycle repeats, and this leads to periodic formation of the chips 
which appears to be like Saw-tooth chips. In the past this has been proposed to be due to the adiabatic shear and subsequent crack initiation.

(iv) The cutting forces extracted from two commercial softwares (i.e. DEFORM-2D and AdvantEdge) were found to be different and incomparable not just due to the way the two different material models are implemented but also the way in which the numerical calculations are performed in estimating the cutting forces, stresses and temperature. In particular, AdvantEdge calculates the dynamic equilibrium in time by an explicit time integration method using a Lagrangian finite element formulation whilst DEFORM is an Implicit solver employing the Newton Raphson technique.

\section{Acknowledgements:}

This work was motivated by the necessity to understand material models to enable working on grants supported by various funders, such as the RCUK (Grant No. EP/S013652/1), H2020 (EURAMET EMPIR A185 (2018)) and Royal Academy of Engineering (Grant No. IAPP18-19 295). The work was carried out in the Centre for Doctoral Training in Ultra-Precision at Cranfield University which is supported by the RCUK via Grants No.: EP/K503241/1 and EP/L016567/1. CL is deeply indebted to the financial support from China Scholarship Council and AECC as well as the technical inputs from Dr Ravi Kant (IIT Ropar), Dr Gasser Abdelal (QUB, Belfast) and Dr Ping Zhou (Dalian, China). Part of this work used ARCHER UK National Supercomputing Service (http://www.archer.ac.uk).

\section{References}

Alvarez, R., R. Domingo and M. A. Sebastian (2011). "The formation of saw toothed chip in a titanium alloy: influence of constitutive models." Strojniški vestnik-Journal of Mechanical Engineering 57(10): 739-749.

Bahi, S., G. List and G. Sutter (2016). "Modeling of friction along the tool-chip interface in Ti6Al4V alloy cutting." The International Journal of Advanced Manufacturing Technology 84(9-12): 1821-1839. 
Bai, W., R. Sun, A. Roy and V. V. Silberschmidt (2017). "Improved analytical prediction of chip formation in orthogonal cutting of titanium alloy Ti6Al4V." International Journal of Mechanical Sciences 133: 357-367.

Cai, J., K. Wang and Y. Han (2016). A Comparative Study on Johnson Cook, Modified Zerilli-Armstrong and Arrhenius-Type Constitutive Models to Predict High-Temperature Flow Behavior of Ti-6Al-4V Alloy in $\alpha+\beta$ Phase. High Temperature Materials and Processes. 35: 297.

Calamaz, M., D. Coupard and F. Girot (2008). "A new material model for 2D numerical simulation of serrated chip formation when machining titanium alloy $\mathrm{Ti}-$ 6Al-4V." International Journal of Machine Tools and Manufacture 48(3-4): 275-288. Calamaz, M., D. Coupard, M. Nouari and F. Girot (2011). "Numerical analysis of chip formation and shear localisation processes in machining the Ti-6Al-4V titanium alloy." The International Journal of Advanced Manufacturing Technology 52(9-12): 887-895.

Che, J., T. Zhou, Z. Liang, J. Wu and X. Wang (2018). "Serrated chip formation mechanism analysis using a modified model based on the material defect theory in machining Ti-6Al-4 V alloy." The International Journal of Advanced Manufacturing Technology 96(9-12): 3575-3584.

Dorlin, T., G. Fromentin and J.-P. Costes (2016). "Generalised cutting force model including contact radius effect for turning operations on Ti6Al4V titanium alloy." The International Journal of Advanced Manufacturing Technology 86(9-12): 3297-3313. Fu, X., G. Chen, Q. Yang, Z. Sun and W. Zhou (2017). "The influence of hydrogen on chip formation in cutting Ti-6Al-4V alloys." The International Journal of Advanced Manufacturing Technology 89(1-4): 371-375.

Gente, A., H.-W. Hoffmeister and C. Evans (2001). "Chip formation in machining Ti6Al4V at extremely high cutting speeds." CIRP Annals-Manufacturing Technology 50(1): 49-52.

Goel, S., I. Llavori, A. Zabala, C. Giusca, S. C. Veldhuis and J. L. Endrino (2018). "The possibility of performing FEA analysis of a contact loading process fed by the MD simulation data." International Journal of Machine Tools and Manufacture 134: 79-80.

Goel, S., A. Stukowski, X. Luo, A. Agrawal and R. L. Reuben (2013). "Anisotropy of single-crystal 3C-SiC during nanometric cutting." Modelling and Simulation in Materials Science and Engineering 21(6): 065004.

Gu, X., C. Dong, J. Li, Z. Liu and J. Xu (2015). "MPM simulations of high-speed and ultra high-speed machining of titanium alloy (Ti-6Al-4V) based on fracture energy approach." Engineering Analysis with Boundary Elements 59: 129-143.

Hua, J. and R. Shivpuri (2004). "Prediction of chip morphology and segmentation during the machining of titanium alloys." Journal of Materials Processing Technology 150(1-2): 124-133.

Inagaki, I., T. Takechi, Y. Shirai and N. Ariyasu (2014). "Application and features of titanium for the aerospace industry." Nippon steel \& sumitomo metal technical report 106: 22-27.

Khan, A. S., R. Kazmi, B. Farrokh and M. Zupan (2007). "Effect of oxygen content and microstructure on the thermo-mechanical response of three Ti-6Al-4V alloys: experiments and modeling over a wide range of strain-rates and temperatures." International Journal of Plasticity 23(7): 1105-1125.

Kotkunde, N., A. D. Deole, A. K. Gupta and S. K. Singh (2014). "Comparative study of constitutive modeling for Ti-6Al-4V alloy at low strain rates and elevated temperatures." Materials \& Design 55: 999-1005. 
KOTKUNDE, N. R. (2012). "Experimental and Numerical Investigations of Forming Behavior in Ti 6Al 4V Alloy at Elevated Temperatures."

Lee, W.-S. and C.-F. Lin (1998). "High-temperature deformation behaviour of Ti6Al4V alloy evaluated by high strain-rate compression tests." Journal of Materials Processing Technology 75(1-3): 127-136.

Leyens, C. and M. Peters (2003). Titanium and titanium alloys: fundamentals and applications, John Wiley \& Sons.

Li, P.-n., X.-y. Qiu, S.-w. Tang and L.-y. Tang (2016). "Study on dynamic characteristics of serrated chip formation for orthogonal turning Ti6Al4V." The International Journal of Advanced Manufacturing Technology 86(9-12): 3289-3296. Man, X., D. Ren, S. Usui, C. Johnson and T. D. Marusich (2012). "Validation of finite element cutting force prediction for end milling." Procedia CIRP 1: 663-668.

Mosleh, A., A. Mikhaylovskaya, A. Kotov, T. Pourcelot, S. Aksenov, J. Kwame and V. Portnoy (2017). "Modelling of the Superplastic Deformation of the Near- $\alpha$ Titanium Alloy (Ti-2.5 Al-1.8 Mn) Using Arrhenius-Type Constitutive Model and Artificial Neural Network." Metals 7(12): 568.

Nemat-Nasser, S., W.-G. Guo, V. F. Nesterenko, S. Indrakanti and Y.-B. Gu (2001). "Dynamic response of conventional and hot isostatically pressed $\mathrm{Ti}-6 \mathrm{Al}-4 \mathrm{~V}$ alloys: experiments and modeling." Mechanics of Materials 33(8): 425-439.

Özel, T. and Y. Karpat (2007). "Identification of constitutive material model parameters for high-strain rate metal cutting conditions using evolutionary computational algorithms." Materials and manufacturing processes 22(5): 659-667. Rashid, W. B., S. Goel, X. Luo and J. M. Ritchie (2013). "The development of a surface defect machining method for hard turning processes." Wear 302(1-2): 11241135.

Ruibin, X. and H. Wu (2016). "Study on cutting mechanism of Ti6Al4V in ultraprecision machining." The International Journal of Advanced Manufacturing Technology 86(5): 1311-1317.

Shalaby, M. A. and S. C. Veldhuis (2018). "Some observations on flood and dry finish turning of the Ti-6Al-4V aerospace alloy with carbide and PCD tools." The International Journal of Advanced Manufacturing Technology 99(9): 2939-2957. Tabei, A., F. Abed, G. Voyiadjis and H. Garmestani (2017). "Constitutive modeling of Ti-6Al-4V at a wide range of temperatures and strain rates." European Journal of Mechanics-A/Solids 63: 128-135.

Upadhyay, V., P. Jain and N. Mehta "Comprehensive study of chip morphology in turning of Ti-6Al-4V." International Journal of Machining and Machinability of Materials 12: 358-371.

Vosough, M., F. Schultheiss, M. Agmell and J.-E. Ståhl (2013). "A method for identification of geometrical tool changes during machining of titanium alloy Ti6Al4V." The International Journal of Advanced Manufacturing Technology 67(1): 339-348.

Vyas, A. and M. Shaw (1999). "Mechanics of saw-tooth chip formation in metal cutting." Journal of Manufacturing Science and Engineering 121(2): 163-172.

Xiulin, S., Z. Shiguang, G. Yang and C. Bin (2015). 3-D Finite Element Simulation Analysis of Milling Titanium Alloy Using Different Cutting Edge Radius. 2015 Sixth International Conference on Intelligent Systems Design and Engineering Applications (ISDEA), IEEE.

Yadav, A. K., V. Bajpai, N. K. Singh and R. K. Singh (2017). "FE modeling of burr size in high-speed micro-milling of Ti6Al4V." Precision Engineering 49: 287-292. 
Yameogo, D., B. Haddag, H. Makich and M. Nouari (2017). "Prediction of the cutting forces and chip morphology when machining the Ti6Al4V alloy using a microstructural coupled model." Procedia CIRP 58: 335-340.

Zhang, Y., X. Han, K. Zheng, Z. Zhang, X. Zhang, J. Fu, Y. Ji, Y.-j. Hao, X.-y. Guo and Z. Wang (2007). "Direct observation of super-plasticity of beta-SiC nanowires at low temperature." Advanced Functional Materials 17(17): 3435-3440. 


\title{
Benchmarking of several material
}

constitutive models for tribology, wear, and other mechanical deformation simulations of Ti6Al4V

\author{
Liu, Cen
}

Elsevier

Liu C, Goel S, Llavori I, et al., (2019) Benchmarking of several material constitutive models for tribology, wear, and other mechanical deformation simulations of Ti6Al4V. Journal of the Mechanical Behavior of Biomedical Materials, Volume 97, September 2019, pp. 126-137 https://doi.org/10.1016/j.jmbbm.2019.05.013 Downloaded from Cranfield Library Services E-Repository 